\title{
Benefit from decline: the primary transcriptome of Alteromonas macleodii str. Te101 during Trichodesmium demise
}

\author{
Shengwei Hou $\mathbb{D}^{1} \cdot$ Mario López-Pérez ${ }^{2}$ - Ulrike Pfreundt ${ }^{1,6} \cdot$ Natalia Belkin $^{3} \cdot$ Kurt Stüber $^{4} \cdot$ Bruno Huettel $^{4}$. \\ Richard Reinhardt ${ }^{4}$. Ilana Berman-Frank ${ }^{3}$ - Francisco Rodriguez-Valera $\mathbb{1}^{2} \cdot$ Wolfgang R. Hess $^{1,5}$
}

Received: 29 June 2017 / Revised: 20 November 2017 / Accepted: 26 November 2017 / Published online: 15 January 2018

(c) The Author(s) 2018. This article is published with open access

\begin{abstract}
Interactions between co-existing microorganisms deeply affect the physiology of the involved organisms and, ultimately, the function of the ecosystem as a whole. Copiotrophic Alteromonas are marine gammaproteobacteria that thrive during the late stages of phytoplankton blooms in the marine environment and in laboratory co-cultures with cyanobacteria such as Trichodesmium. The response of this heterotroph to the sometimes rapid and transient changes in nutrient supply when the phototroph crashes is not well understood. Here, we isolated and sequenced the strain Alteromonas macleodii str. Te101 from a laboratory culture of Trichodesmium erythraeum IMS101, yielding a chromosome of $4.63 \mathrm{Mb}$ and a single plasmid of $237 \mathrm{~kb}$. Increasing salinities to $\geq 43 \mathrm{ppt}$ inhibited the growth of Trichodesmium but stimulated growth of the associated Alteromonas. We characterized the transcriptomic responses of both microorganisms and identified the complement of active transcriptional start sites in Alteromonas at single-nucleotide resolution. In replicate cultures, a similar set of genes became activated in Alteromonas when growth rates of Trichodesmium declined and mortality was high. The parallel activation of $f i A, r p o S$ and of flagellar assembly and growth-related genes indicated that Alteromonas might have increased cell motility, growth, and multiple biosynthetic activities. Genes with the highest expression in the data set were three small RNAs (Aln1a-c) that were identified as analogs of the small RNAs CsrB-C in E. coli or RsmX-Z in pathogenic bacteria. Together with the carbon storage protein A (CsrA) homolog Te101_05290, these RNAs likely control the expression of numerous genes in responding to changes in the environment.
\end{abstract}

Shengwei Hou and Mario López-Pérez are co-sharing first authors.

Electronic supplementary material The online version of this article (https://doi.org/10.1038/s41396-017-0034-4) contains supplementary material, which is available to authorized users.

WolfgangR. Hess

wolfgang.hess@biologie.uni-freiburg.de

1 Faculty of Biology, University of Freiburg, Schänzlestr. 1, D-79104 Freiburg, Germany

2 Evolutionary Genomics Group, División de Microbiología, Universidad Miguel Hernández, Apartado 18, San Juan 03550 Alicante, Spain

3 Mina and Everard Goodman Faculty of Life Sciences, Bar-Ilan University, Ramat Gan 52900, Israel

4 Max Planck-Genome-Centre Cologne, Carl-von-Linné-Weg 10, D-50829 Köln, Germany

5 Freiburg Institute for Advanced Studies, University of Freiburg, Albertstr. 19, D-79104 Freiburg, Germany

6 Present address: ETH Zürich, Department of Civil, Environmental and Geomatic Engineering, Institute of Environmental Engineering, Stefano-Franscini-Platz 5, CH-8093 Zürich, Switzerland

\section{Introduction}

Trichodesmium is a marine cyanobacterium greatly impacting the biogeochemical cycles of carbon and nitrogen in the oligotrophic subtropical and tropical oceans [1]. Trichodesmium forms expansive blooms at the surface of the ocean that are easily tracked by satellites [2]. When these blooms decay, large amounts of nutrients are released into the sea [1, 3]. Recent DNA-based research into the microbial community associated with Trichodesmium suggested complex metabolic interactions and far-reaching ecological implications [4-7], which called for detailed studies of how these microbial associations work. The nearly ubiquitous presence of Alteromonas in natural Trichodesmium samples [8] and their multifaceted capabilities of recycling marine dissolved organic carbon [9] point to the scientific value of understanding this particular interaction in more detail. Focusing on the phytoplankton physiology, the effects of an Alteromonas co-culture with phytoplankton including Prochlorococcus [10-12] and the diatom Phaeodactylum tricornutum [13] were studied. Total 
gene expression has been studied also in environmental Trichodesmium blooms [14], but there is no transcriptome study specifically targeting the heterotroph in these interactions.

Heterotrophic gammaproteobacteria that typically occur at a rather low abundance in oligotrophic marine or freshwater habitats [15] can thrive under eutrophic, nutrientenriched, conditions [16]. When organic material of marine origin was incubated on-board ships or in mesocosms, dense populations of gammaproteobacteria such as Alteromonas were observed repeatedly [17-19]. Alteromonas have large cells and genomes and can grow rapidly when nutrients are abundant [20]. In offshore oligotrophic pelagic habitats and in most oligotrophic tracts of the central ocean gyres, the transient nutrients discharged from particulate organic matter provide opportunities for the swift growth of Alteromonas [21-23]. In fact, growing evidence indicates that the oligotrophic ocean is a heterogeneous environment with tiny, transient nutrient patches appearing regularly, for example, from fecal pellets or sinking dead phytoplankton, thus providing nutrient gradients at the microscale. These "hot-spots" favor motile copiotrophic bacteria such as Alteromonas [24-26]. Although the available Alteromonas genomes do not recruit a large number of reads from most metagenomes [27-29], metatranscriptomic analyses have supported Alteromonas as an active constituent of the ocean microbial community with high transcriptional activities despite its low representation in metagenomes [17, 30, 31].

Most published Alteromonas genomes demonstrate relatively conserved synteny over their core, which allows the precise identification of variable regions, such as flexible genomic islands (fGIs) [32]. In comparison, Alteromonas transcriptomes are poorly characterized. One study investigated the responses of Alteromonas to different environmental parameters using two closely related deepsea ecotype strains isolated from the same environmental sample [33]. Another transcriptomic analysis showed that the co-cultivation of Alteromonas macleodii MIT1002 with Prochlorococcus significantly impacted the physiology of the latter [34]. However, neither the impact of the associated cyanobacterium on Alteromonas nor the gene expression in an expanding population co-existing with a dense primary producer has been elucidated to date.

Here, we isolated and sequenced Alteromonas macleodii strain Te101 (from here: Alteromonas Te101) from a culture of Trichodesmium erythraeum IMS101 (from here: Trichodesmium IMS101), with which it had been co-existing for years. Raising the salinity from 37 to 43 parts per thousand (ppt) in these cultures inhibited the growth of Trichodesmium but stimulated the growth of Alteromonas, which tolerates up to $180 \mathrm{ppt}$ salinity [28]. We isolated the total RNA from biological replicate cultures at $43 \mathrm{ppt}$ salinity and parallel cultures with healthy Trichodesmium IMS101 (37 ppt). Using differential RNA sequencing (dRNA-Seq) [35], we inferred the complement of active transcription start sites (TSSs) of Alteromonas Te101 at single-nucleotide resolution. The analysis of differentially expressed genes revealed the activation of a carbon storage regulator $\mathrm{A}$ and $\mathrm{B}-\mathrm{C}$ (CsrA-CsrB-C)-like regulatory mechanism at the heart of the response to Trichodesmium decay.

\section{Materials and methods}

\section{Culturing conditions, RNA preparation, and transcriptome sequencing}

Non-axenic Trichodesmium IMS101 cultures were grown in YBCII [36] at $25^{\circ} \mathrm{C}$ under a 12:12 light-dark cycle at $\sim 80$ $\mu \mathrm{mol}$ photons $\mathrm{m}^{-2} \mathrm{~s}^{-1}$ white light. During exponential growth, biomass of associated bacteria (predominantly Alteromonas) is generally negligible compared with the cyanobacterial biomass. However, stress conditions leading to high mortality of Trichodesmium enhanced the growth of associated bacteria. Subsamples were collected for chlorophyll $a$ extraction by boiling in $90 \%$ methanol and spectrophotometric analysis at $664 \mathrm{~nm}$ [37] every 1-3 days. On day 9 , the extracts were scanned for pigment absorbance between 520 and $760 \mathrm{~nm}$ using a Cary 300 (Agilent Technologies) spectrophotometer. For transcriptome analysis, two replicate batch cultures were grown at $37 \mathrm{ppt}$ (normal YBCII) or $43 \mathrm{ppt}$ (increased salt concentration by adding $\mathrm{NaCl}$ to $736 \mathrm{mM}$ ) for 9 days in $1 \mathrm{~L}$ Pyrex bottles with air bubbling and harvested in the middle of the light phase.

Two replicate dRNA-Seq complementary DNA (cDNA) libraries were constructed for each of the two conditions, yielding four 5'P-dependent Terminator Exonuclease (TEX) processed dRNA-Seq libraries. For each dRNA-Seq library, a minus library was prepared from the same TEX-processed sample, which was not further treated with tobacco acid pyrophosphatase before 5 ' linker ligation, resulting in sequencing the left-over processed transcripts. In order to cover the full length of the transcripts, one additional cDNA library was constructed by pooling aliquots from the four samples for classical RNA-Seq analysis in which the TEX treatment was omitted (RNA-Seq library). Single-end transcriptome sequencing was performed on the Illumina HiSeq 2000 sequencing system with a read length of $100 \mathrm{nt}$. After adapter removal and quality trimming, $>40$ million and 18 million reads were generated for each of the dRNA-Seq and minus libraries, separately. Details of RNA isolation and library preparation were presented previously [38, 39]. 


\section{Strain isolation and genomic sequencing}

Alteromonas Te101 was isolated from Trichodesmium IMS101 cultures by dilution and plating on marine agar (12\% sea salt (Sigma), $0.5 \%$ peptone, $0.1 \%$ yeast extract, and $1.5 \%$ agar). Single colonies were then grown in liquid culture (12\% sea salt (Sigma), $0.5 \%$ peptone, and $0.1 \%$ yeast extract) at $25^{\circ} \mathrm{C}$. Genomic DNA for Single Molecule Real Time (SMRT) sequencing analysis was extracted from $80 \mathrm{~mL}$ cultures collected by centrifugation. The pellet was re-suspended in $1 \mathrm{~mL}$ SET on ice $(25 \%$ (w/v) sucrose, 1 $\mathrm{mM}$ EDTA, and $50 \mathrm{mM}$ Tris, $\mathrm{pH}$ 7.5). One-fourth volume of $0.5 \mathrm{M}$ EDTA, $2 \%$ sodium dodecyl sulfate, and $1.5 \mathrm{mg}$ proteinase K (Sigma) were added for cell lysis at $50{ }^{\circ} \mathrm{C}$ overnight. Following phenol/chloroform extraction, one volume of 2-propanol (Roth, Germany) was added for DNA precipitation at room temperature for $30 \mathrm{~min}$. The precipitate was washed once in $\mathrm{H}_{2} \mathrm{O} / 2$-propanol (1:1) and once in 2-propanol, followed by $10 \mathrm{~min}$ centrifugation at 10,000 $\mathrm{g}$ at $4{ }^{\circ} \mathrm{C}$. The pellet was washed with $70 \% \mathrm{EtOH}$, dried for $10 \mathrm{~min}$, and re-suspended in $100 \mu \mathrm{L} \mathrm{H}_{2} \mathrm{O}$. One $\mu \mathrm{L}$ of RNase A (Sigma) was added and the tube was incubated at $37^{\circ} \mathrm{C}$ with shaking at $260 \mathrm{rpm}$ overnight. RNase was removed by another round of phenol extraction and precipitation. The DNA was re-suspended in $75 \mu \mathrm{L} \mathrm{H}_{2} \mathrm{O}$ and quantified using Quant-iT® PicoGreen ${ }^{\circledR}$ dsDNA Reagent (Invitrogen). DNA libraries were prepared according to the large SMRTbell gDNA protocol (Pacific Biosciences) with a 10$\mathrm{kb}$ insert size. Genomic DNA was sequenced with a PacBio RS II platform. Generated reads were trimmed and de novo assembled using the HGAP workflow version 2 (Pacific Biosciences). Genomes were annotated using PGAAP (http://www.ncbi.nlm.nih.gov/genome/annotation_prok/).

\section{Bioinformatic methods}

fGIs were identified as regions where synteny ( $\geq 10 \mathrm{~kb})$ was broken between genomes of different isolates [40]. To detect these genomic islands and to assess genome rearrangements, reciprocal BLASTN and TBLASTX searches between the Alteromonas Te101 and previously assembled Alteromonas genomes [28] were performed. The Average Nucleotide Identity (ANI) between strains was calculated using the JSpecies software v1.2.1 with default parameters [41]. The COG database [42] was used to identify conserved proteins requiring an e-value $<1 \mathrm{e}^{-5},>80 \%$ query coverage, and $>30 \%$ identity. Concatenated proteins were aligned with Kalign [43], and a maximum likelihood tree was generated by FastTree [44] using a JTT + CAT model and gamma approximation.

For transcriptome analysis, we followed the workflow for read cleaning and quality control described by [35]. Reads from all libraries were aligned to the Alteromonas Te101 genome at $99 \%$ identity using segemehl v0.2.0 [45]. For TSS identification, a replicate-assisted background subtraction algorithm was designed and applied. A TSS located within $200 \mathrm{nt}$ upstream of an annotated protein-coding gene or giving rise to reads overlapping such a gene was classified as a gene TSS (gTSS). A TSS located within an annotated gene or antisense to it (plus $50 \mathrm{nt}$ up or downstream) was classified as an iTSS or aTSS, respectively. A TSS located in an intergenic region or upstream of a non-coding (nc)RNA, including small RNA (sRNA), ribosomal RNA (rRNA), and transfer RNA (tRNA) genes, was designated a non-coding TSS (nTSS). The implementation of this algorithm can be found at https://github.com/housw/GRPutils/blob/master/tss_analysis_ pipline.sh.

For differential expression analysis, the TSS counts were normalized using the Trimmed Mean of M-values method in edgeR v3.14.0 [46]. Dispersions were estimated by treating samples between 37 and 43 ppt as replicates using the quantile-adjusted conditional maximum likelihood method, and TSSs that were differentially expressed between 43 and 37 ppt were called by the exactTest function in edgeR with an adjusted $p$-value cutoff of 0.05 .

Potential CsrA-binding sites were searched with the regular expression "GGA[ACGT] $\{4,70\}$ GGA[ACGT] $\{2,12\}$ \$" [47] and additionally by using the CSRA_TARGET algorithm [48]. To detect potential promoter motifs, sequences $200 \mathrm{nt}$ upstream of the TSSs were scanned by XXmotif [49]. A more detailed version of the bioinformatics analyses can be found in the Supplementary Information.

\section{Accession information}

A. macleodii Te101 has been deposited in the DSMZ culture collection (no. DSM 104636). PacBio raw reads, genome sequences, and annotations have been deposited at NCBI under BioProject ID PRJNA355640. Primary transcriptomic reads can be found at NCBI Sequence Read Archive under BioProject ID PRJNA237745.

\section{Results and Discussion}

\section{Microbial community associated with Trichodesmium at different salinities}

Non-axenic Trichodesmium IMS101 cultures were grown in YBCII media for 9 days at salinities of $30,37,43$, and 48 ppt, in two replicates for each treatment. Trichodesmium grew exponentially at the lower salinities ( 30 and $37 \mathrm{ppt}$ ) that represent the salinity range from estuarine to oceanic waters with an average salinity of $35 \mathrm{ppt}$ in pelagic surface oceans [50, 51] (Figs. 1a, b). Growth rates declined, 
(a)

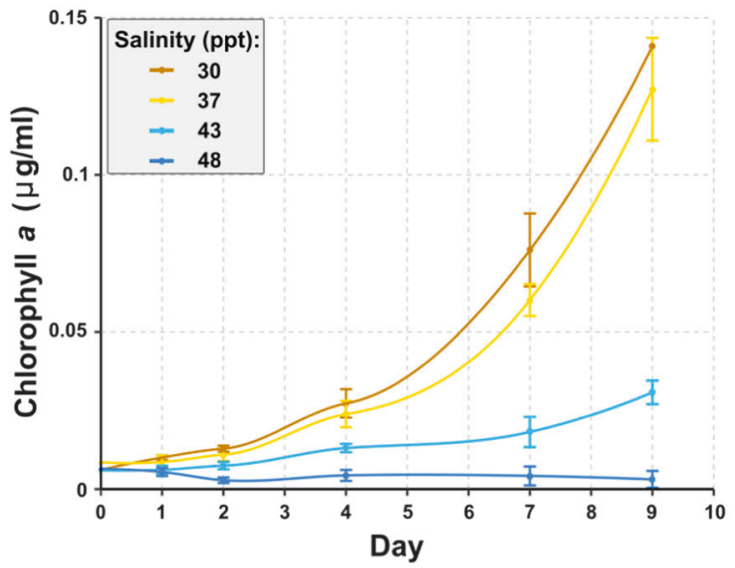

(c)

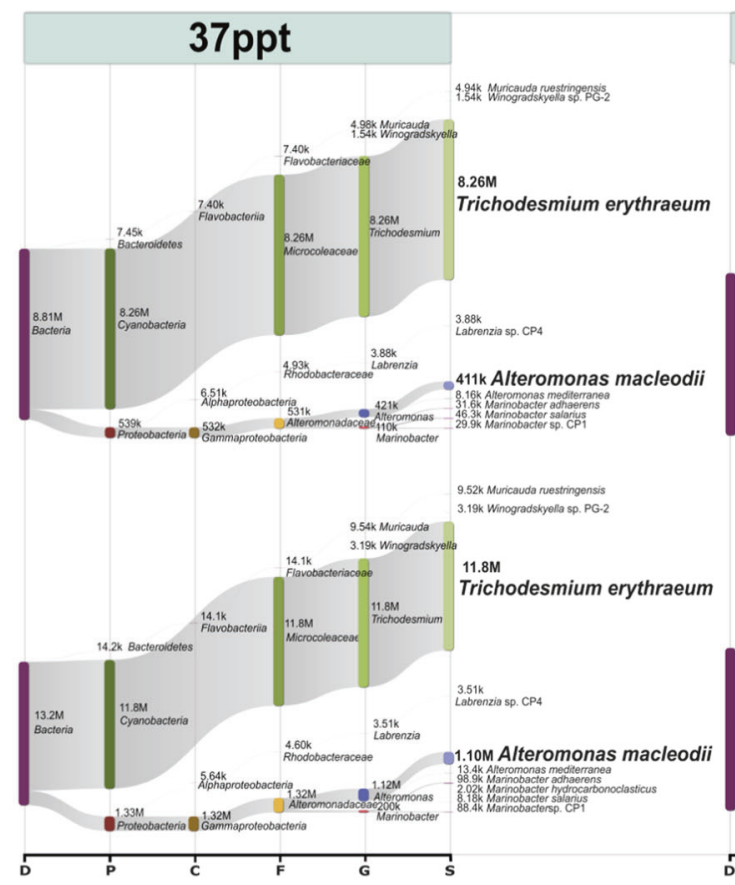

Fig. 1 Chlorophyll $a$ concentration $\mathbf{a}$ and cell growth rates $\mathbf{b}$ of Trichodesmium cultures at different salinities. The error bars represent standard errors in a and standard deviations in b. Only exponential growth phase (days 2-9) was considered in calculating the cell growth rates in b. c Hierarchical taxonomy assignment of metatranscriptome reads. Non-rRNA reads of dRNA-Seq libraries were used for

although biomass still increased, when ambient salinity was increased to 43 ppt (Figs. 1a, b) [38], while growth was severely inhibited at $48 \mathrm{ppt}$ salinity, as shown by the spectral scan of pigments (Figure S1). Although Trichodesmium also thrives in high salinity waters such as in the Gulf of Aqaba (Red Sea; salinity 40.8) [52, 53], our data show that salinities $\geq 43 \mathrm{ppt}$ induce great stress, declining growth rates, and enhanced mortality. (b)
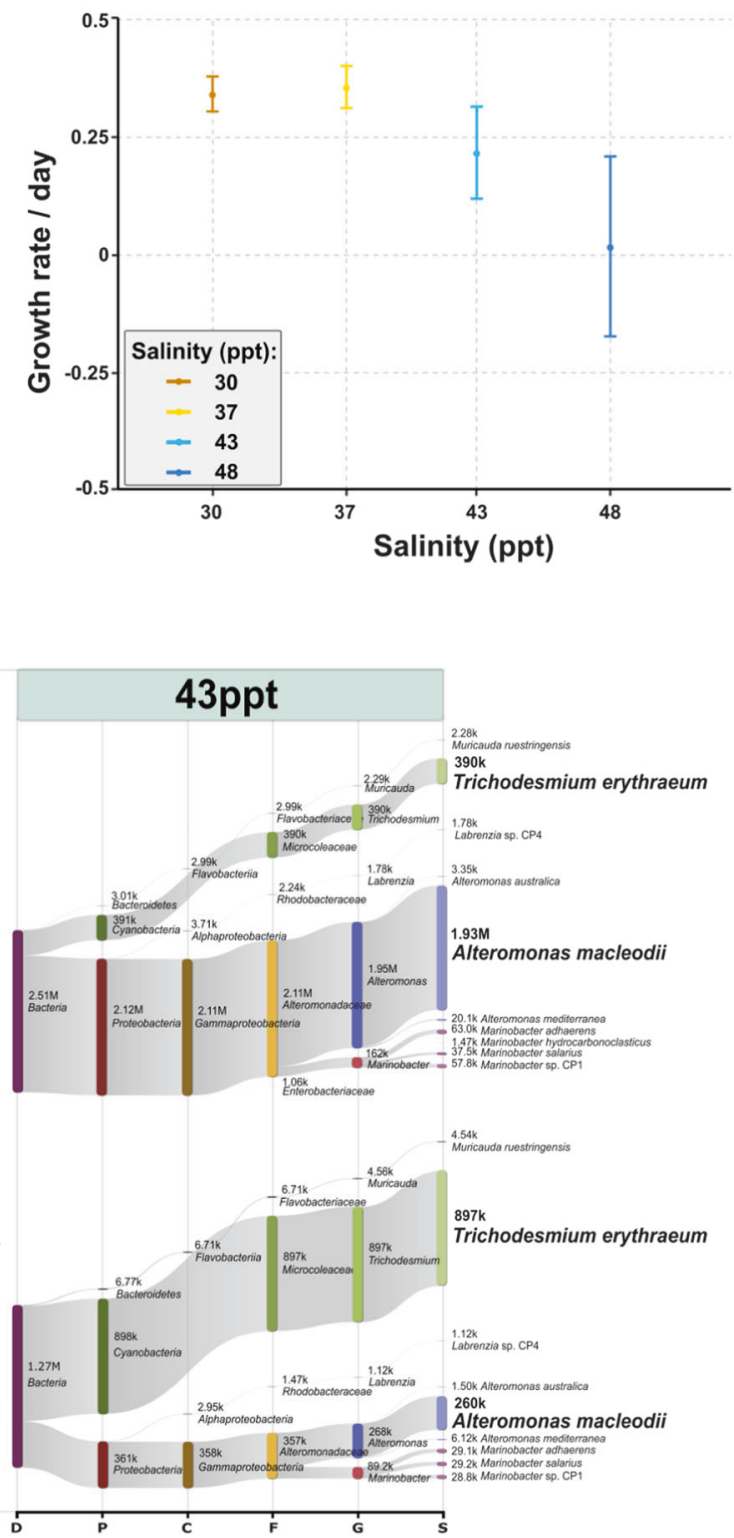

taxonomy assignment with Centrifuge [105]. Taxa were aligned hierarchically from domains to species. The number of assigned reads was shown on top or next to each taxon. Only taxa recruiting $>1000$ reads are shown. $\mathrm{D}$ domain, $\mathrm{P}$ phylum, $\mathrm{C}$ class, $\mathrm{F}$ family, $\mathrm{G}$ genus, $\mathrm{S}$ species, $\mathrm{M}$ million, $\mathrm{K}$ thousand

This increase in salinity affected the composition of the microbial community, as shown here by the hierarchical taxonomic classification of transcriptome reads (Fig. 1c). At $37 \mathrm{ppt}$ salinity, $\sim 90 \%$ of assignable reads were classified as Trichodesmium erythraeum in both replicates, $4.6 \%$ and $8.4 \%$ of assignable reads were classified as Alteromonas and a minor number of reads were classified as Marinobacter. In contrast, at $43 \mathrm{ppt}$ at the same day, the 
assignable read share of Trichodesmium was $14.1 \%$ in replicate 1, whereas the share of Alteromonas and Marinobacter increased to $70.6 \%$ and $5.9 \%$, respectively. In replicate 2, the relative abundance of Trichodesmium was also lower (65.4\%), and the share of Alteromonas (19.5\%) and Marinobacter (6.5\%) higher, although less pronounced than in replicate 1 . Hence, although developing with different dynamics, the expanding Alteromonas Te101 populations in both replicates provided the opportunity to investigate its transcriptome composition in the context of stressed Trichodesmium.

\section{Comparative genomic features of Alteromonas Te101}

We are unaware of an axenic isolate of Trichodesmium IMS101 and the presence of co-occurring gammaproteobacteria is well known [8]. Through multiple dilution and streak cultivation, we segregated an axenic Alteromonas strain from a non-axenic culture of Trichodesmium IMS101. Based on its 16S rRNA sequence, the strain was classified as belonging to the species A. macleodii. The strain isolation was repeated from the continuously propagated cultures after 1 year and $16 \mathrm{~S}$ sequencing confirmed the previously identified Alteromonas.

Using SMRT sequencing, complete sequences of the $4.63 \mathrm{Mb}$ chromosome and a single plasmid of $237 \mathrm{~kb}$, named pTE101, were recovered (Table 1). A phylogenomic tree inferred from 1015 concatenated core proteins (Fig. 2a) confirmed the initial 16S-based phylogeny of Alteromonas Te101 and demonstrated its clustering with other $A$. macleodii strains, sharing an ANI $>95 \%$. We used strain 'English Channel 673' (ANI 98.1\%) for comparison because its genome is complete and well annotated [28].

Owing to the well-preserved synteny among the members of this genus, we detected 14 fGIs in the chromosome harboring ca. 8\% (298/3920) of all genes (Fig. 2b, Table S1). These fGIs contain clusters of flexible genes that occupy equivalent genomic locations in different Alteromonas strains [54]. Two major classes of fGIs have been defined: additive fGIs, which are recombination hotspots for the integration of various different alien genes, and replacement fGIs, which also contain different but functionally related genes for outer layer glycoproteins or polysaccharides [32]. Four replacement fGIs were previously described in Alteromonas [32], and A. macleodii 673 and Alteromonas Te101 have different versions of three of them. However, both strains share a nearly identical flagellum glycosylation island, despite the temporal and geographical distances between the isolates (Fig. 2b). In both strains, the additive fGIs contain long gene cassettes, such as integrons and mobilizable genomic islands and mobile genetic elements (transposons), or are related to specific
Table 1 Genome information for Alteromonas Te101 and composition of the primary transcriptome for the two tested conditions

\begin{tabular}{lll}
\hline Alteromonas Te101 & Chromosome & Plasmid \\
\hline Genome size (bp) & $4,630,082$ & 237,311 \\
Scaffolds & 1 & 1 \\
GC content (\%) & 44.7 & 41.7 \\
Coding density (\%) & 88 & 85 \\
Median intergenic distance (bp) & 94 & 66 \\
CDS & 3,920 & 239 \\
tRNA & 72 & 0 \\
rRNA & 16 & 0 \\
Total number of TSS & 2,181 & 99 \\
Number of gTSS (total \%) & $1,282(58.78)$ & $33(33.33)$ \\
Number of aTSS (total \%) & $130(5.96)$ & $16(16.16)$ \\
Number of iTSS (total \%) & $595(27.28)$ & $35(35.35)$ \\
Number of nTSS (total \%) & $174(7.98)$ & $15(15.15)$ \\
TSS detected at 37 ppt condition & 1,365 & 66 \\
Number of gTSS (total \%) & $892(65.35)$ & $27(40.91)$ \\
Number of aTSS (total \%) & $99(7.25)$ & $11(16.67)$ \\
Number of iTSS (total \%) & $225(16.48)$ & $19(28.79)$ \\
Number of nTSS (total \%) & $149(10.92)$ & $9(13.64)$ \\
TSS detected at 43 ppt condition & 1,928 & 80 \\
Number of gTSS (total \%) & $1,179(61.15)$ & $29(36.25)$ \\
Number of aTSS (total \%) & $80(4.15)$ & $11(13.75)$ \\
Number of iTSS (total \%) & $515(26.71)$ & $28(35.00)$ \\
Number of nTSS (total \%) & $154(7.99)$ & $12(15.00)$ \\
\hline
\end{tabular}

metabolic features, such as alginate degradation and metal resistance (Fig. 2b).

Comparison of the pTE101 plasmid sequence revealed a region of $\sim 140 \mathrm{~kb}$ encoding the machinery for conjugal transfer and plasmid maintenance that is highly syntenic with A. macleodii 673 plasmid pAMDE1-300 (Fig. 2b). In the flexible region, both plasmids contain multiple insertion sequence elements and gene clusters involved in heavy metal resistance, whereas a previously identified hybrid NRPS-PKS cluster [55] is restricted to pAMDE1-300.

\section{The primary transcriptome architecture of Alteromonas Te101 differs from other bacteria}

We identified 2280 TSSs for the Alteromonas Te101 chromosome and plasmid pTe101 active at least at one condition. Of these, $57.7 \%$ were gTSSs, $27.6 \%$ iTSSs, $8.3 \%$ nTSSs, and $6.4 \%$ aTSSs (for an explanation of the different types of TSSs please refer to Bioinformatic methods section); a total of 2008 were active at 43 ppt, and 1431 at 37 ppt salinity (Table 1 ). The median $5^{\prime}$-untranslated region (UTR) length was $63 \mathrm{nt}$, but we also found 10 leaderless transcripts and 34 long 5'-UTRs (>200 nt), pointing to different modi of post-transcriptional regulation (Figure S2, 
(a)

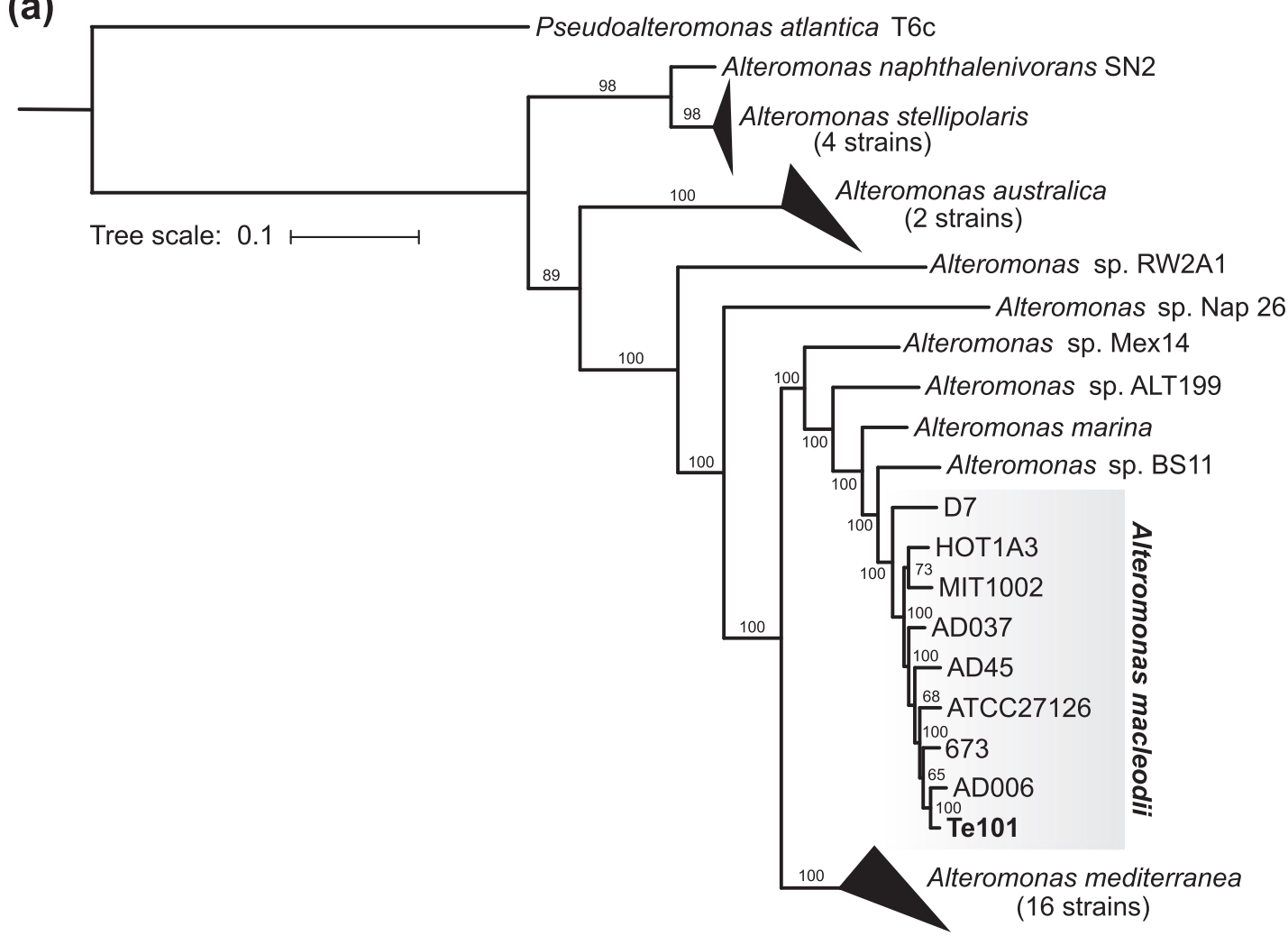

(b)

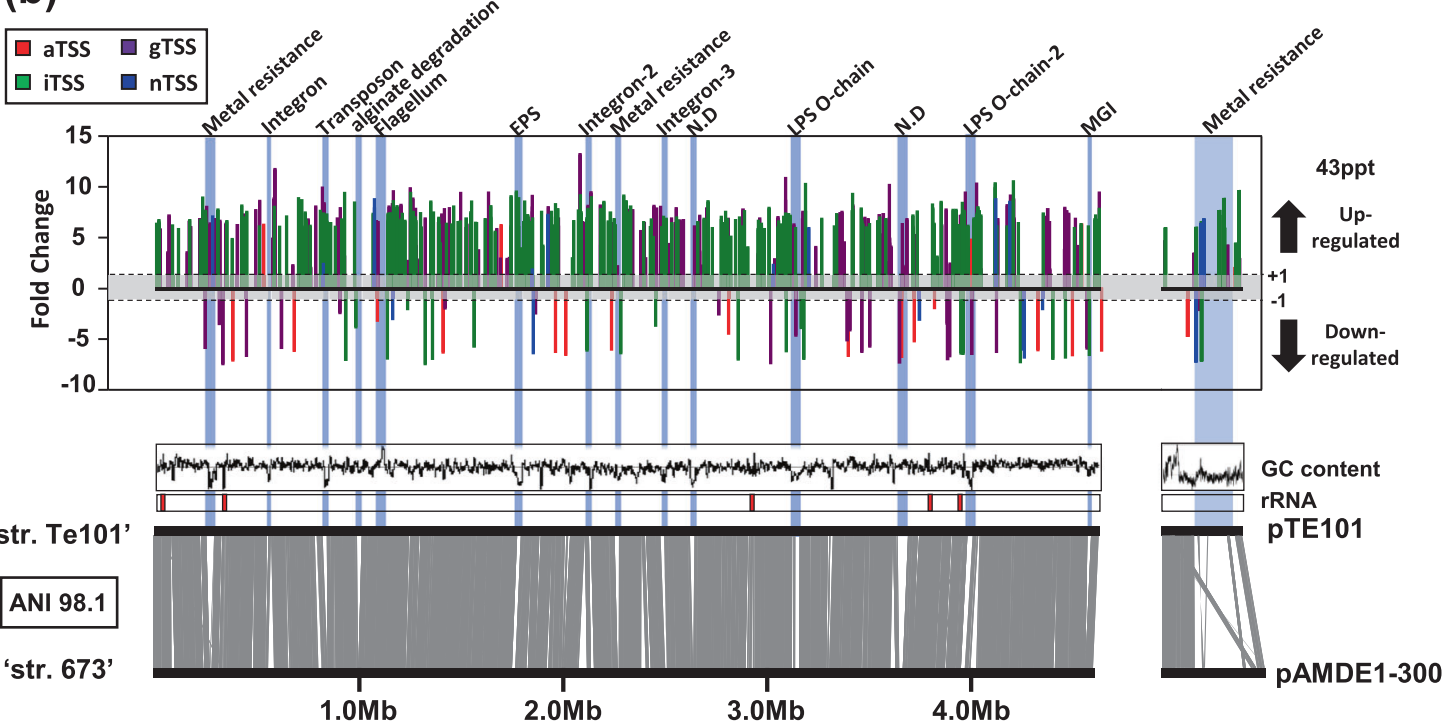

Fig. 2 a Phylogenetic relationships between Alteromonas Te101 and other members of the genus Alteromonas. The tree is based on a concatenated set of 1015 proteins from the shared core proteome of all available Alteromonas genomes and Pseudoalteromonas atlantica T6c, which was used as an outgroup. The numbers at branches represent bootstrap values in percent. b Flexible genomic islands (fGIs) and differentially expressed TSSs. Differentially expressed TSSs are visualized on the upper panel, the $y$ axis shows the $\log _{2^{-}}$

Table S2). The 1315 gTSSs were associated with 1191 annotated genes, of which 108 had more than one gTSS, indicating more complex transcriptional regulation. transformed fold changes. Genomic-wide synteny and fGIs (vertical blue rectangles) are shown on the lower panel. The chromosome of the A. macleodii 'English Channel 673' was used as a reference to detect fGIs in the Alteromonas Te101 chromosome. In the same way, the plasmid pTE101 was compared against the plasmid pAMDE1-300 of A. mediterranea strain DE1. If known, the fGI's function is given on top. N.D represents not determined. For the list of genes within these fGIs, see Table $\mathrm{S} 1$

Although the different percentages of predicted TSS types should be considered with caution since there are differences in the growth conditions or the definition of transcript 
types, the share of gTSSs was considerably higher in Alteromonas Te101 (Figure S3) than in other bacteria and archaea, for example, $30 \%$ in the co-cultured Trichodesmium IMS101 [39], 50.4\% in Xanthomonas campestris B100 [56] and $17.3 \%$ in Prochlorococcus sp. MIT9313 [57]. Conversely, high numbers of aTSSs have been reported in several bacteria, including Trichodesmium [39, $53,56,58-62]$, whereas only $\sim 6 \%$ of all TSSs in Alteromonas Te101 were classified as aTSS (Table 1). These results suggest differences in the transcriptome architecture of Alteromonas Te101 compared with other bacteria (Figure S3). The genome-wide visualization of identified TSSs and transcriptome coverage is shown in Supplementary Dataset 1.

\section{Multiple regulators are involved in the lifestyle decision to activate flagellum biosynthesis and motility}

Principal component analyses revealed that the Alteromonas transcriptomes were qualitatively highly similar at $43 \mathrm{ppt}$ salinity in both replicates compared with the transcriptomes at $37 \mathrm{ppt}$ (Figure S4). The divergence between the replicates at $37 \mathrm{ppt}$ might be due to low sequencing depth, which can be sensitive to variations of culture conditions. In addition, the different growth stages of Alteromonas cannot be excluded, which might be affected by uncontrolled environmental and uncharacterized biological factors. Nevertheless, similar transcriptional activities were observed at 43 ppt, which allows us to determine differentially expressed genes robustly. Thus, the replicates were fed into differential expression analysis to identify the TSSs that were up or downregulated at 43 ppt. The list of TSSs and their expression levels under both conditions, fold changes, and a global overview of their distribution along the chromosome are given in Figure S5, Table S3 and Supplementary Dataset 1.

Benefiting from the precise identification of TSS, our primary transcriptomic data makes it possible to compare promoter activities across different conditions. Compared with the classical RNA-Seq based quantification, TSS-based quantitative analysis provides a higher resolution for genes with multiple TSSs, and for genes with abundant internal transcripts. Applying a $\log _{2}$-transformed fold change $(\log F C) \geq 1$ and a false discovery rate $<0.05$, we identified 504 and 56 significantly up or downregulated genes, respectively (Tables S4 and S5). Although 43 ppt does not appear to induce conspicuous stress in Alteromonas, consistent with the reported stability of Alteromonas up to a salinity of $180 \mathrm{ppt}$ [28], we analyzed the salt-specific responses in this study. The basic mechanism to deal with high osmolarity is the accumulation of compatible solutes including amino acids and derivatives such as glycine betaine, proline, and ectoine. These pathways were not differentially expressed (sodium/proline symporter TE101_ 09200, TE101_06005; choline transporter TE101_00375, TE101_14030, TE101_16255, TE101_08845) (Table S3), indicating that Alteromonas could deal with the tested salinity differences without transcriptional changes for these genes. However, we cannot exclude the possibility that Alteromonas Te101 benefitted from the uptake of large quantities of homoserine betaine, which is the major compatible solute of Trichodesmium IMS101 [38]. Our results showed that for Alteromonas, one homeostatic mechanism in response to a slight variation in salinity was the activation of $\mathrm{K}^{+}$and $\mathrm{Na}^{+}$transporters (TE101_03025, TE101_06605).

Among several terms, Gene Ontology (GO) analysis revealed "localization of cell" and "movement of cell or subcellular component" as enriched terms within the biological process domain for TSSs upregulated at $43 \mathrm{ppt}$ (Fig. 3a and Table S6). Consistent with this classification, 34 upregulated TSSs were found within the motility gene cluster alone. Two of these serve the regulator FliA (sigma 28, gene TE101_05165), which allows the expression of genes belonging to the late operon and genes encoding components of the flagellar filament, such as the flagellar hook protein (FliD; TE101_04980), the flagellar export chaperone FliS (TE101_04985), or flagellins (FliC; TE101_04960 and TE101_04970). Several upregulated genes encode proteins involved in sensing and responding to environmental cues (Table S7). Only a single iTSS, possibly a post-transcriptional regulator located in the flagellum glycosylation fGI, was downregulated (Fig. 3b). These data clearly showed that flagellar filament synthesis was stimulated at $43 \mathrm{ppt}$. This observation is consistent with a report using quantitative video microscopy of bacteria swarming around a lysing diatom cell and a resource utilization model, which revealed that motile, chemotactic copiotrophs have a competitive advantage over non-motile cells when a phytoplankton bloom collapses [25].

In addition to the sigma factor FliA, we found four more upregulated sigma factors: RpoS (sigma S, Te101_02645), RpoN (sigma 54; TE101_05050), RpoH (sigma 32; TE101_17790), and RpoE (sigma 24; TE101_13105). The homologs of the latter three in Escherichia coli (E. coli) are involved in nitrogen metabolism regulation, and the responses to heat shock and cell surface stress [63]. RpoS (74\% identity with E. coli RpoS) [64] was, with a $\operatorname{logFC}$ of 11.6 (iTSS-578989), the second-most strongly induced gene at 43 ppt (Table S4). This finding implied that RpoS in Alteromonas Te101 was one of the main regulators during the tested growth condition. In E.coli, RpoS is important for survival during nutrient deprivation or the stationary phase of growth [65]. In a broader set of bacteria, RpoS is often considered as a general stress response factor because it 


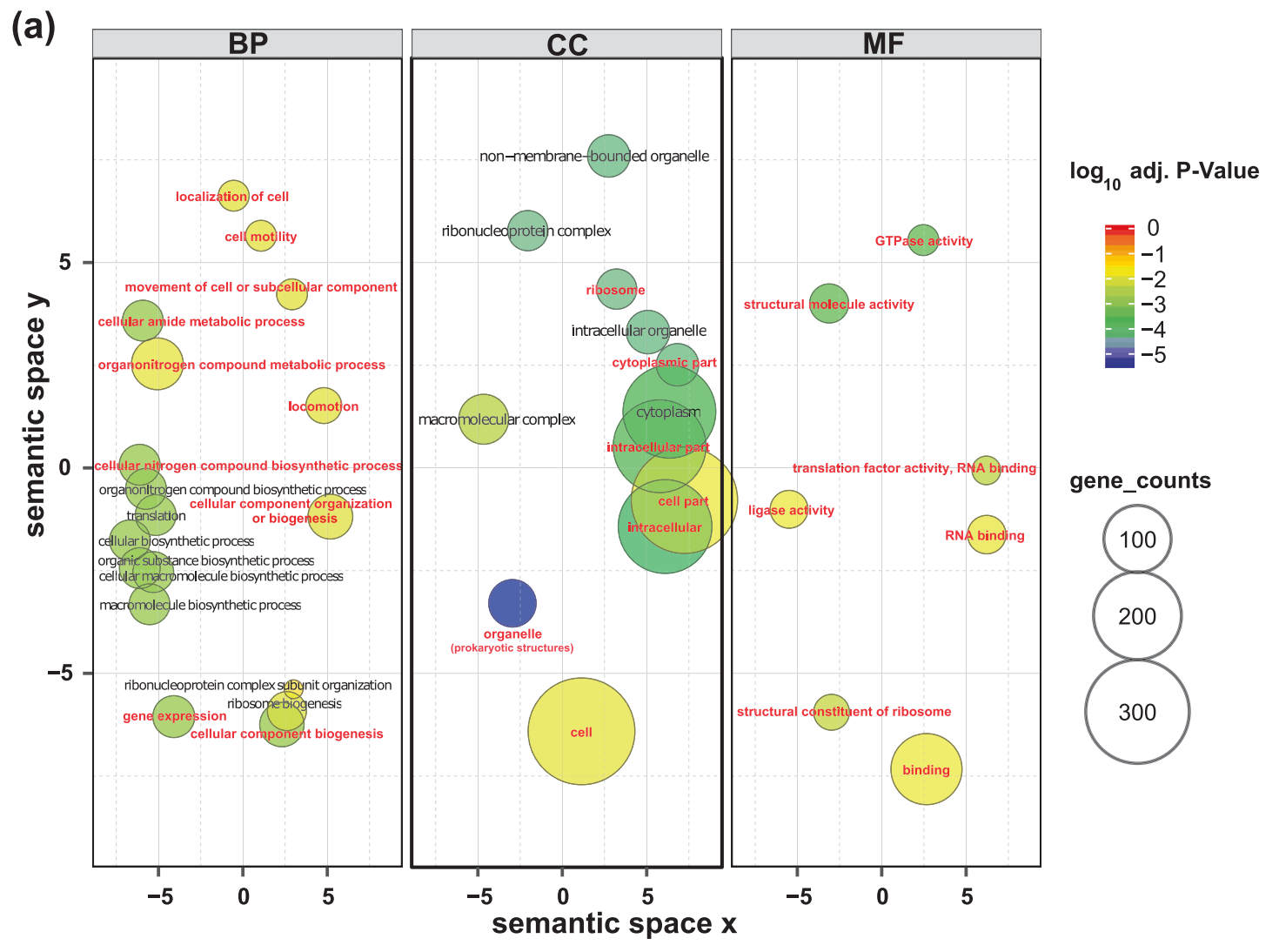

(b)
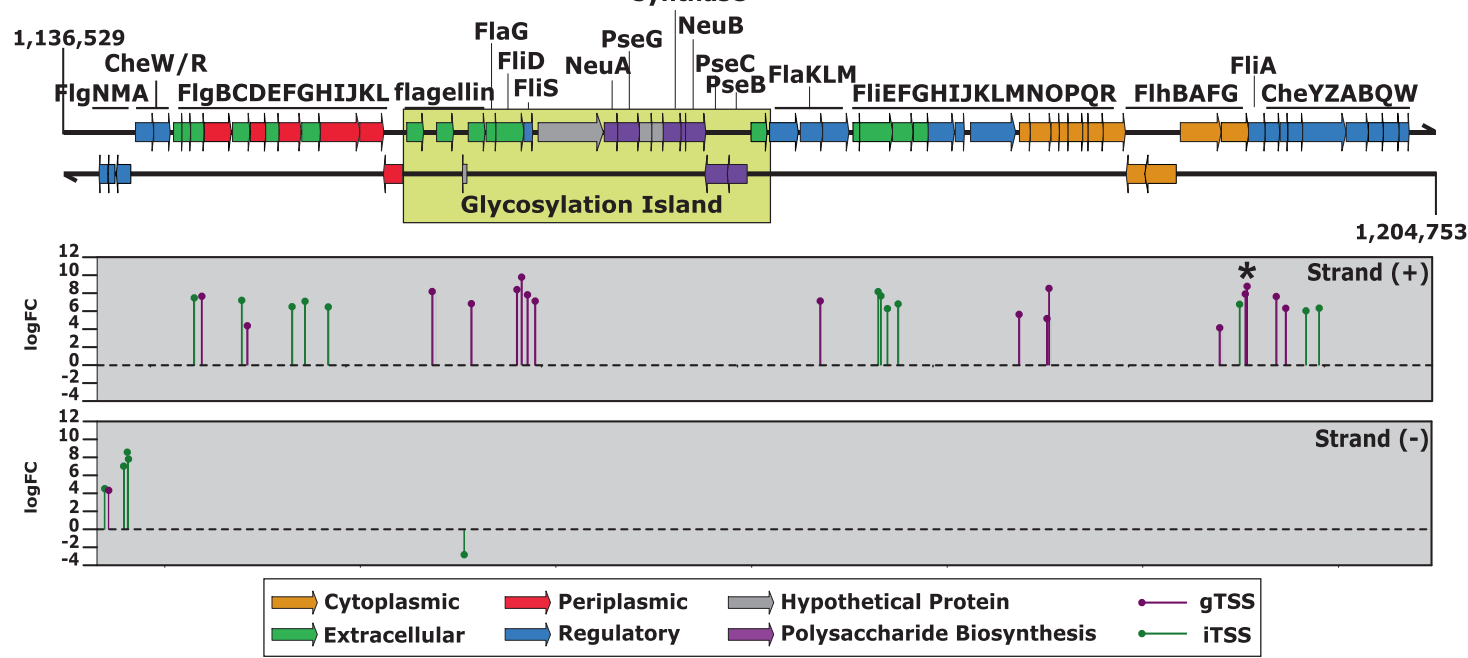

Fig. 3 a Enriched GO terms for genes upregulated at 43 ppt. In order to cluster semantically similar GO terms together and to reduce redundancy, pairwise semantic similarities of enriched GO terms were calculated using REVIGO with the SimRel method [106]. Terms with a dispensability $<0.4$ were taken as representatives and highlighted in bold font and red color, redundant terms are shown in black. Only GO terms with an adjusted $p$-value $<0.05$ are shown. Circle sizes correspond to the counts of differentially expressed genes involved in that
GO term. BP biological process, CC cellular component, MF molecular function. b Expression of the flagellar gene cluster. TSSs differentially expressed at $43 \mathrm{ppt}$ are indicated in the lower two panels, separately for the forward and the reverse strand. Two strongly activated TSSs for the fliA gene are highlighted with an asterisk symbol. The variable region is highlighted by the yellow box. $\log \mathrm{FC} \log _{2^{-}}$ transformed fold changes 
governs the expression of multiple genes that mediate physiological changes related to osmotic, $\mathrm{pH}$, oxidative, and heat stresses, and the production of virulence factors. In the marine bacterium Vibrio cholera, the rpoS knockout mutant was deficient in its capacity to produce or secrete an extracellular protease [66]. An rpoS-deficient mutant of Salmonella enterica serovar Typhimurium showed significant attenuation in virulence [67]. Furthermore, a previous RNA-seq study in $A$. mediterranea where the transcriptional response to different growth conditions (including starvation) was investigated showed that rpoS was not differentially expressed when comparing starvation with growth in rich medium [33]. These data suggest that in Alteromonas, and probably other opportunistic microbes, RpoS is involved in acclimation responses to changing environments as it is one of the most critical stress acclimation factors and not only in nutrient deprivation conditions [65, 68]. Moreover, RpoS in E. coli is associated with biofilm formation [69], and the repression of flagellar gene transcription during the exponential growth phase $[70,71]$. However, the here observed parallel activation of fliA and rpoS suggests the stimulation of multiple physiological processes, including motility, acclimation to higher salinity, and likely the assimilation of Trichodesmium-released nutrients. Consistent with the activated expression of these alternative sigma factors, the transcription of the vegetative sigma factor 70 (TE101_03190) decreased. These results suggest that the activation of flagellum biosynthesis and motility is under the control of multiple regulators and part of a complex lifestyle decision.

In the Trichodesmium primary transcriptome, increased expression of homoserine methyltransferase (Tery_2447) was observed at 43 ppt salinity (Table S8), consistent with its function in the synthesis of the major compatible solute homeserine betaine [38]. In contrast, the impaired growth of Trichodesmium at higher salinities (Figs. 1a, b) correlated with the downregulation of genes involved in major cellular component and compound biogenesis or photosynthesis (Table S8, S9).

\section{Implications for the marine nitrogen and carbon cycles}

Alteromonas are copiotrophic bacteria that are commonly found in oceanic phytoplankton bloom and mesocosm studies [17, 20, 72-74]. The physiological and metabolic activities of Alteromonas affect the interacting organisms and contribute to the biogeochemical cycling of carbon and nitrogen in the marine environment [21, 22, 24, 25]. Our transcriptomic data allow detailed insight into the genetic underpinnings of how Alteromonas metabolism changes upon phytoplankton decay.
Some of the marine MG-II/III Euryarchaeota are capable of utilizing extracellular proteins and peptides for rapid heterotrophic growth [75-77]. Among bacteria, Alteromonas from the Arctic Chukchi Sea was identified to have major proteolytic activities [78]. Based on previously established methods [35, 75], we identified 154 genes encoding peptidases in Alteromonas Te101, which belong to 67 MEROPS peptidase subfamilies (Table S10). The six genes encoding extracellular S08A peptidases were the most actively transcribed peptidase subfamily members at both salinities (Fig. 4a; Tables S3 and S10). We identified an $18 \mathrm{nt}$ imperfect palindrome at a conserved position around 30-50 nt upstream of the gTSS of two S08A family peptidase genes and of seven other genes (Fig. 4b, motif 6 in Table S11), indicative of potential concerted regulation of these genes by the same regulator. Other upregulated proteases included the ATP-dependent ClpA (TE101_08955, with the highest $\operatorname{logFC}$ of 13.1, Table S4), ClpX (TE101_13295), and zinc metalloprotease TE101_09120. These highly expressed proteases degrade misfolded proteins but can also degrade regulatory proteins [79] or imported extracellular peptides. These data indicate that Alteromonas expressed a suite of extra- and intracellular peptidases for the utilization of external proteins at both salinities, consistent with observations that proteolysis provides the major source of amino acids for rapid de novo protein synthesis [80].

Alteromonas can utilize a wide range of organic carbon sources, including glucose [81] and complex polymeric compounds such as alginate, agarose, and other polysaccharides [82, 83]. Thus, Alteromonas could utilize the carbohydrates released from Trichodesmium such as transparent exopolymeric particles [84, 85]. Analysis of the expression level of carbohydrate active enzymes (CAZy) showed that glycosyltransferase family 2 (GT2) genes were actively transcribed in both salinities, whereas carbohydrate esterase family 11 (CE11) and glycosyltransferase family 47 (GT47) exhibited strongly increased transcription at 43 ppt (Table S12).

\section{A CsrA-B-C-like system in Alteromonas}

Genome-wide TSS analyses allow the identification of sRNAs, which frequently function as post-transcriptional regulators [86]. In addition to the conserved bacterial ncRNAs, RNase P RNA, SRP RNA, tmRNA, rRNAs, and 6S RNA, we identified 127 sRNAs from the chromosome and 11 from the plasmid pTE101. Remarkably, in both salinities, $\sim 87 \%$ of all primary reads were associated with nTSSs, and most of these reads originated from an intergenic region of only $404 \mathrm{bp}$ containing three nTSSs (Fig. 5a). We identified three sRNAs originating from this genomic region and named them Aln1a, Aln $1 \mathrm{~b}$ and $\mathrm{Aln} 1 \mathrm{c}$ 


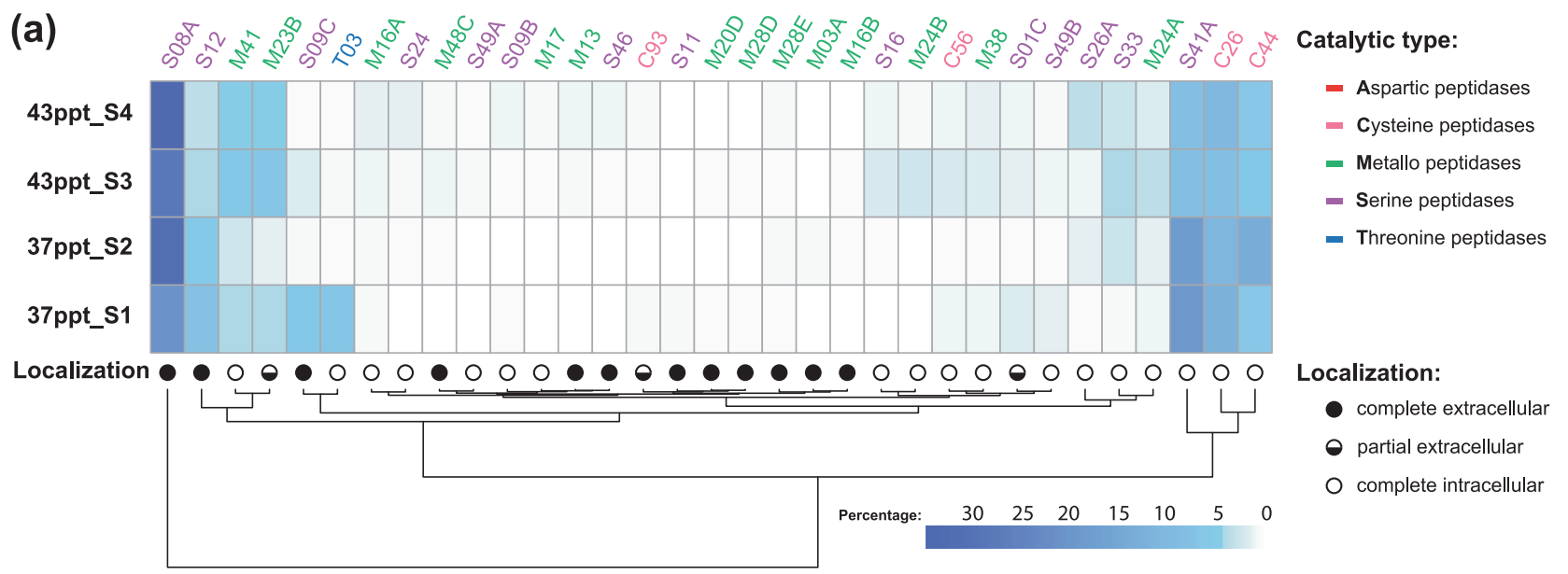

(b)
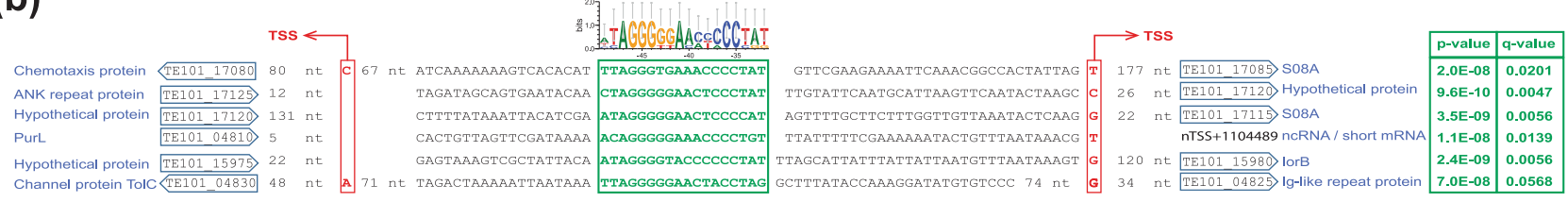

Fig. 4 a Expression of peptidases in Alteromonas Te101. For each MEROPS subfamily, gTSS counts were summed and the percentage from the total peptidase-associated gTSS count from all four samples was used for visualization. Only subfamilies with a column sum $\geq 1 \%$ are shown. Columns were clustered using complete linkage hierarchical clustering based on Euclidean distances. Predicted localizations of peptidase subfamilies are given at the ends of the branches. b The promoter regions of two S08A extracellular peptidase genes, of

iorB (TE101_15980) encoding isoquinoline 1-oxidoreductase, of TE101_17120 encoding a hypothetical protein and of nTSS + 1104489 , from which an sRNA or a short mRNA is transcribed, share the presence of a palindromic sequence element (boxed in green) at a conserved distance to the TSS (boxed in red). The $p$-value and $q$-value columns show the probabilities and false discovery rates of finding these motifs against the whole genome

for Alteromonas sRNA 1a-c. These sRNAs share 99-96\% nucleotide identity among A. macleodii and $77 \%$ identity, on average, to homologous sequences in the $11 \mathrm{~A}$. mediterranea strains (Fig. 5b). A previous RNA-seq study revealed the high expression of this region, comparable to ribosomal genes, in A. mediterranea [33]. To check expression of the Aln1 sRNAs in situ, we mapped an existing marine metatranscriptomic data set to the genome of A. macleodii Te101. In this data set, which tracked biomass demise of oceanic Trichodesmium populations [19], we detected high expression and upregulation of these three sRNAs. Hence, we conclude that Aln1a-c and their analogs must play a conserved role in some copiotrophic bacteria, at least across the genus level of Alteromonas.

Aln1a-c share a similar secondary structure with a high frequency of $\mathrm{A}(\mathrm{N}) \mathrm{GGA}$ motifs in the single-stranded regions, which is the typical binding motif of the CsrA protein $[48,87]$ (Fig. 5b). Homologs of the enterobacterial CsrA exist in other bacteria, where they are also called repressor of stationary phase metabolites (Rsm) or catabolite repression control ( $\mathrm{Crc})$ in Pseudomonas [88, 89]. These proteins are sequence-specific RNA-binding proteins that alter the translation and/or stability of mRNA targets

[90, 91] and are themselves controlled by binding to antagonistic sRNAs of the RsmX-Z/CsrB-C family [92, 93] detected in a wide range of bacteria, including Enterobacteriaceae, Legionella pneumophila, Erwinia, Vibrio, and Pseudomonas [94-99]. RsmX-Z/CsrB-C sRNAs share the occurrence of multiple binding sites for CsrA and Rsm, respectively, with which they can sequester and antagonize the respective regulatory proteins. Notably, Alteromonas Te101 possesses a CsrA (TE101_05290) homolog, as shown by the $87 \%$ sequence identify with the E. coli homolog and the presence of likely autoregulatory $\mathrm{A}(\mathrm{N})$ GGA motifs in its ribosome binding region. We conclude that Aln1a-c, together with the protein Te101_05290, constitute the Alteromonas homolog of the CsrA-B-C system. Moreover, whereas Aln1a was driven by the most active promoter under both conditions, the additional activation of Aln $1 \mathrm{~b}$ and Aln $1 \mathrm{c}$ transcription at 43 ppt (Fig. 5a and Table S4) suggests that this system plays an important role in the regulation of copiotrophic lifestyle decisions.

We subsequently estimated the potential targets of the Alteromonas Te101 CsrA-Aln1a-c system (Table S13). The availability of the precise $5^{\prime}$-UTR sequences was advantageous for this analysis, and 126 potential CsrA target genes were predicted. To include potential targets 
(a)

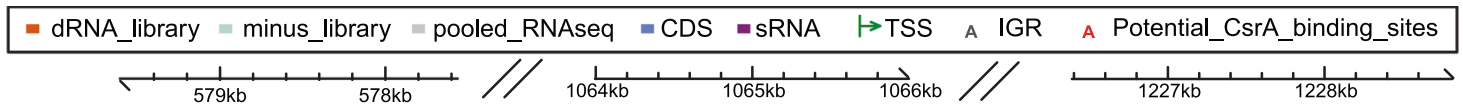
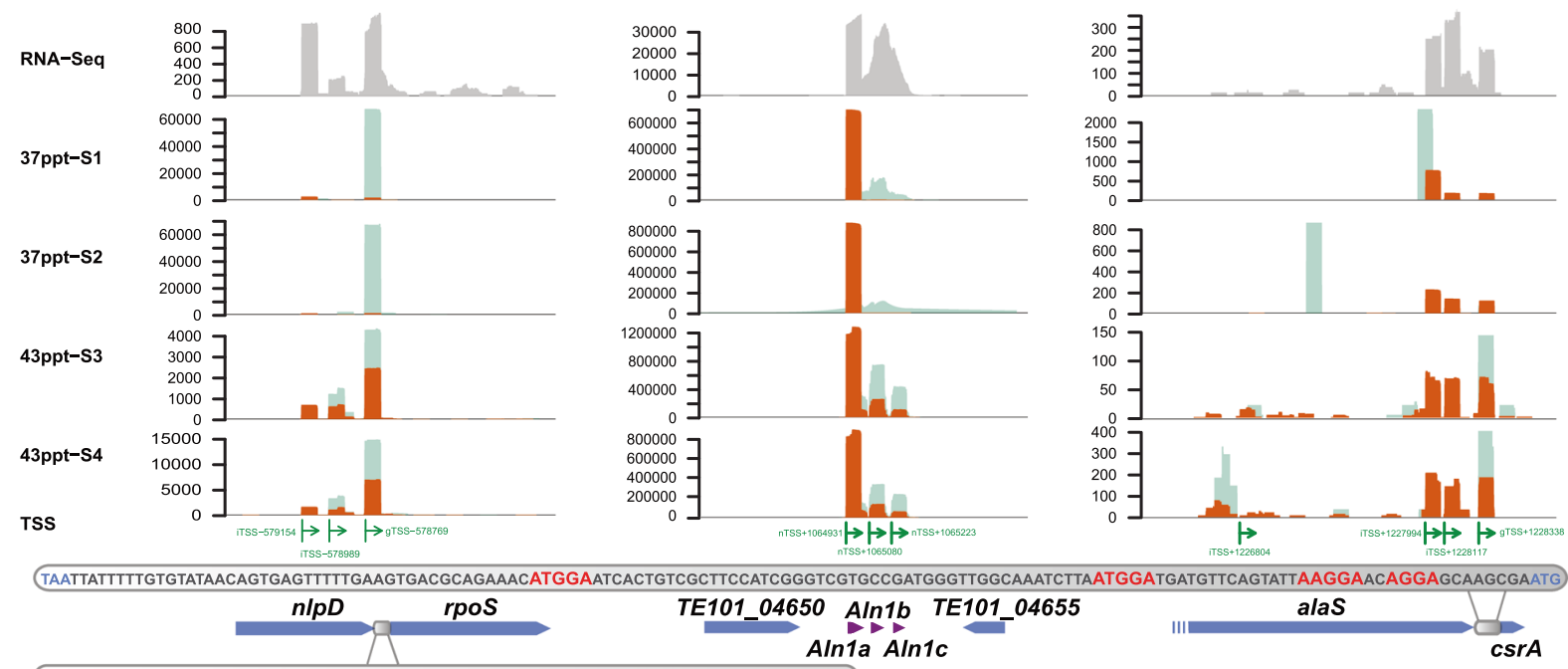

\section{TAATAAAAATAAATAACAATAAAAAAAGACAAAGGAGAAACGTCATAAGGTAAACCTTGTAGCAGGAGATTCATG}

(b)

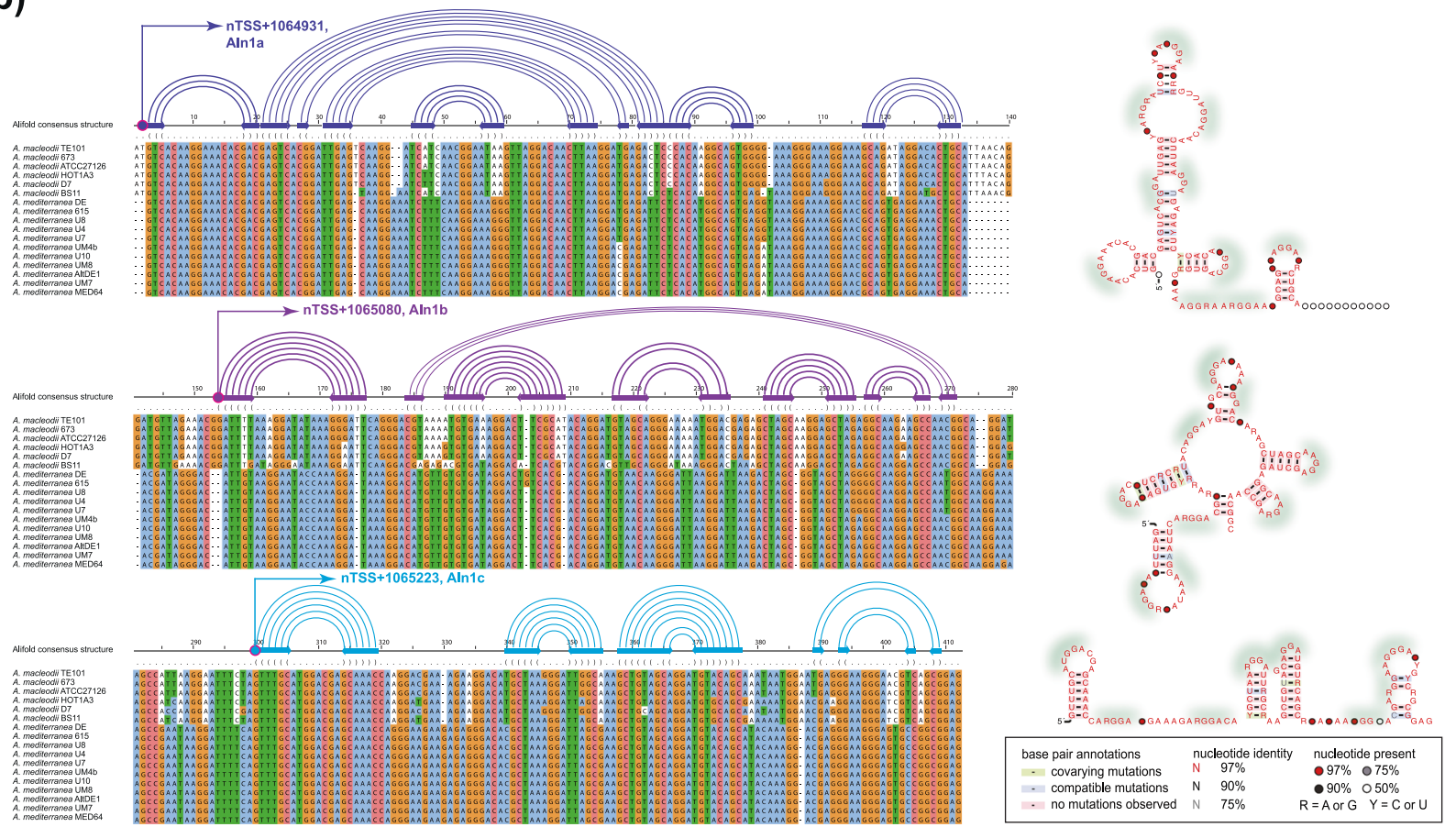

Fig. 5 a Promoters and read coverage of rpoS, Aln1a-c, and $c s r A$ genes at 37 and 43 ppt. The potential CsrA-binding sites within the rpoS and csrA $5^{\prime}$-UTRs are highlighted in red. The three sRNAs (Aln1a-c) originate from the $404 \mathrm{nt}$ intergenic region between the genes Te101_04650 and Te101_04655 from three distinct nTSSs.

without an associated $5^{\prime}$-UTR, we applied the CSRA_TARGET algorithm to scan the intergenic regions and $5^{\prime}$ ends of genes, yielding 35 additional targets (Table S13). Consistent with recent findings in Legionella pneumophila b Multiple sequence alignment and predicted secondary structures of Aln1a-c. Identified TSSs are indicated by curved arrows on top of each sequence block. Conserved base-pairing are connected with arc curves on top of the alignments. Potential CsrA-binding sites are highlighted by green shadows in the right panel

[100], both rpoS and csrA may be repressed by CsrA in Alteromonas Te101 by blocking the respective ribosome binding sites (Fig. 5a). In addition, multiple genes associated with ribosomes, flagella, the cell cycle and DNA 


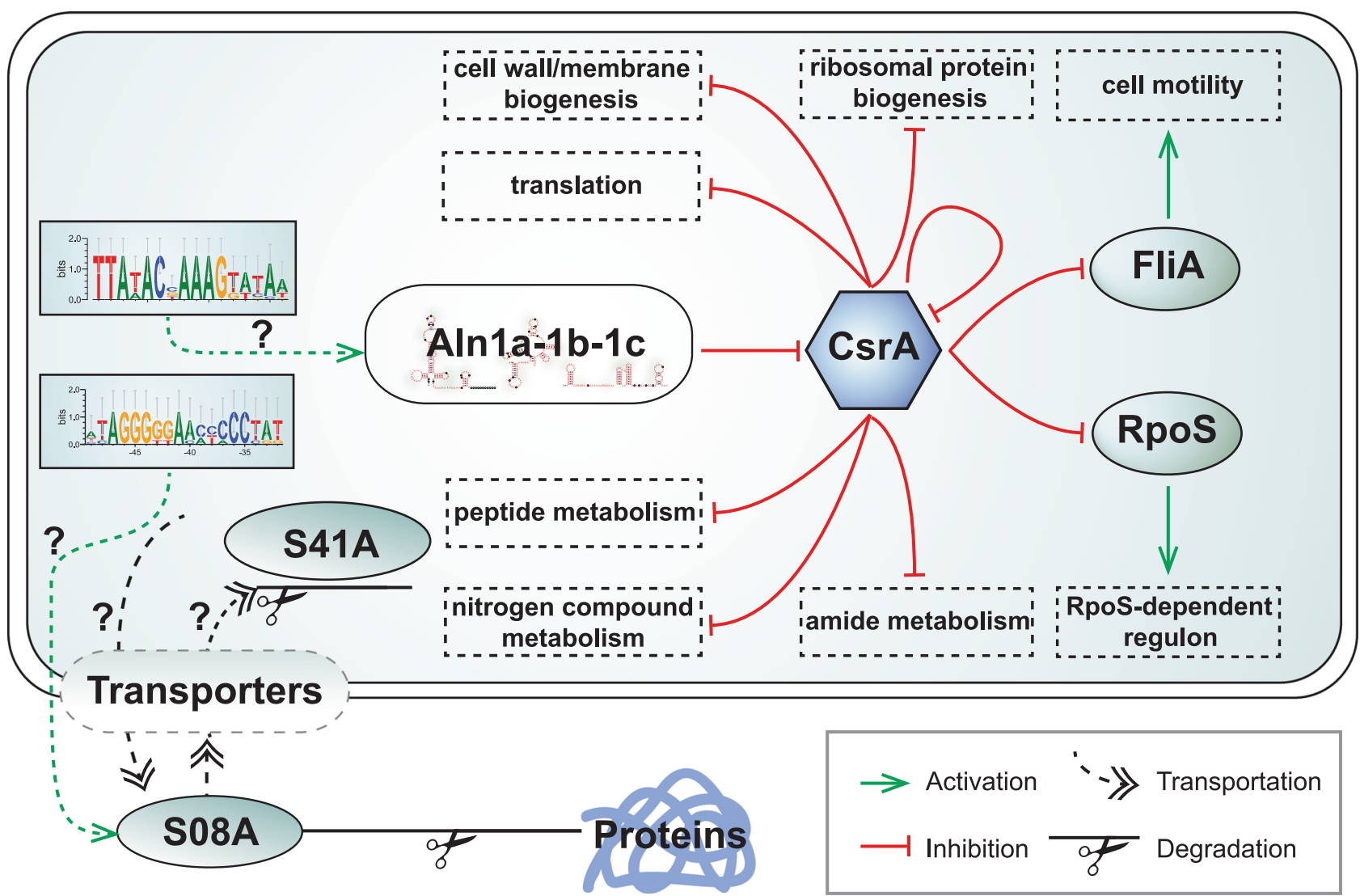

Fig. 6 Proposed regulatory mechanisms in Alteromonas Te101 during transition to copiotrophic growth. Aln1 sRNA transcription becomes stimulated at 43 ppt. The additional Aln1 sRNAs sequester CsrA. Thus, the target mRNAs translationally repressed by CsrA become relieved. Key regulatory proteins such as RpoS become translated and activate a downstream cascade of events. Hence, the RpoS regulon is activated under nutrient-rich conditions, contrary to the situation in enterobacteria where $\mathrm{RpoS}$ is associated with stressful conditions including nutrient deprivation. Five of the predicted CsrA targets share the presence of a sequence motif within their promoters with the Aln 1a gene (Figure S6), which may mediate their concerted regulation through an unknown regulator in a feed-forward manner. The stimulated transcription of peptidases and transport systems sustains the hydrolysis and uptake of external proteins. Question marks represent hypothesized or unknown regulatory mechanisms

and co-repressed by CsrA. The csrA gene is transcribed from three distinct TSSs, all of which were downregulated at 43 ppt (Fig. 5a). Hence, our results point to a central function of the CsrA-Aln1a-c system in the control of copiotrophic growth when organic matter becomes available (Fig. 6). Both the lowered transcription of csrA and the activated transcription of Aln1 sRNAs led to less available CsrA. Thus, the CsrA-mediated repression of translation becomes relieved, thereby stimulating peptide and nitrogen metabolism, ribosome biosynthesis and translation, membrane and cell wall biogenesis.

In addition to fundamental physiologic processes, these events can affect cellular behavior, that is, motility. Previous studies revealed that CsrA regulates biofilm formation [101], activates the expression of the flagellar operon $f h D C$ in E. coli [92], regulates virulence factors [102], and impacts carbon metabolism and quorum sensing [103, 104]. Therefore, the predicted targets and observed regulatory changes linked to the Alteromonas Te101 CsrA-Aln1 
system resemble the functions of the CsrA-B-C system in pathogenic bacteria. However, in its own ecological context, the CsrA-Aln1 system provides Alteromonas with a one-for-all solution to transiently activate all downstream pathways to benefit from nutrient hot-spots appearing in its environment.

\section{Conclusions}

The first primary transcriptome of an opportunistic marine bacterium responding to lysing phytoplankton is presented. Our data suggest the different pathways by which copiotrophs can benefit during stochastic inputs of organic matter that appear in an otherwise nutrient-poor oligotrophic environment. The assembly and growth of the flagellar filament, protein synthesis, proteolysis, and modification of the structure of the phospholipid bilayer were all significantly upregulated under our 43 ppt experimental condition, which impaired growth of the otherwise dominant cyanobacteria Trichodesmium. Our transcriptome data further indicate that Alteromonas secretes extracellular peptidases such as S08A to facilitate the assimilation of released nutrients. Single-nucleotide resolution promoter mapping allowed the identification of complex regulatory mechanisms that are involved in these processes. Major upregulated sigma factors were RpoS (sigma S) and FliA (sigma 28). Alteromonas employs CsrA and the three CsrAsequestering sRNAs, Aln1a-c, as a system for posttranscriptionally regulating the expression of up to 161 genes. We conclude that the CrrA-Aln1a-c system constitutes a major mechanism involved in the integration of copiotrophic growth when transient nutrient hotspots appear, possibly guiding cellular decisions between the metabolically expensive, yet competitive motile and the inexpensive, non-motile lifestyle.

Acknowledgements This work was supported by the EU project MaCuMBA (grant agreement no. 311975) to WRH and FRV and by the German Israeli Foundation grant no. 1133 to IB-F and WRH. Support of ML-P by a postdoctoral fellowship from the Valencian Consellería de Educació, Investigació, Cultura i Esport (APOSTD/2016/051) and of SH by the China Scholarship Council is gratefully acknowledged. We thank Viktoria Reimann for expert technical assistance and Dr. Rahul Kulkarni for sharing the source code of CSRA_TARGET. The authors are grateful for the constructive comments and suggestions from three anonymous reviewers.

Author contributions UP, NB, IB-F, and WRH designed the experiment; NB measured growth dynamics; UP prepared the samples for sequencing and isolated Alteromonas Te101; KS, BH and RR performed SMRT sequencing. ML-P performed the comparative genomics analysis. SH and WRH designed the TSS prediction and transcriptome analysis pipeline. SH implemented the TSS prediction algorithm, performed the TSS and sRNA identification and transcriptome analysis. SH and ML-P prepared all the figures and tables.
SH, ML-P, UP, and WRH wrote the manuscript with contributions from all authors.

\section{Compliance with ethical standards}

Conflict of interest The authors declare that they have no conflict of interest.

Open Access This article is licensed under a Creative Commons Attribution 4.0 International License, which permits use, sharing, adaptation, distribution and reproduction in any medium or format, as long as you give appropriate credit to the original author(s) and the source, provide a link to the Creative Commons license, and indicate if changes were made. The images or other third party material in this article are included in the article's Creative Commons license, unless indicated otherwise in a credit line to the material. If material is not included in the article's Creative Commons license and your intended use is not permitted by statutory regulation or exceeds the permitted use, you will need to obtain permission directly from the copyright holder. To view a copy of this license, visit http://creativecommons. org/licenses/by/4.0/.

\section{References}

1. Edward J. Carpenter and Douglas G. Capone. Chapter 4 Nitrogen Fixation in the Marine Environment. In Nitrogen in the Marine Environment (2nd Edition). San Diego: Elsevier/Academic Press; 2008. p 141-98.

2. Dupouy C, Neveux J, Subramaniam A, Mulholland MR, Montoya JP, Campbell L, et al. Satellite captures Trichodesmium blooms in the southwestern tropical Pacific. Eos Trans Am Geophys Union. 2000;81:13-16.

3. Bergman B, Sandh G, Lin S, Larsson J, Carpenter EJ. Trichodesmium - a widespread marine cyanobacterium with unusual nitrogen fixation properties. FEMS Microbiol Rev. 2013; 37:286-302.

4. Frischkorn KR, Rouco M, Van Mooy BAS, Dyhrman ST. Epibionts dominate metabolic functional potential of Trichodesmium colonies from the oligotrophic ocean. ISME J. 2017;11: 2090-101.

5. Hmelo LR, Van Mooy BAS, Mincer TJ. Characterization of bacterial epibionts on the cyanobacterium Trichodesmium. Aquat Microb Ecol. 2012;67:1-14.

6. Rouco M, Haley ST, Dyhrman ST. Microbial diversity within the Trichodesmium holobiont. Environ Microbiol. 2016;18:5151-60.

7. Sheridan CC, Steinberg DK, Kling GW. The microbial and metazoan community associated with colonies of Trichodesmium spp.: a quantitative survey. J Plankton Res. 2002;24:913-22.

8. Lee MD, Walworth NG, McParland EL, Fu F-X, Mincer TJ, Levine NM, et al. The Trichodesmium consortium: conserved heterotrophic co-occurrence and genomic signatures of potential interactions. ISME J. 2017;11:1813-24. https://doi.org/10.1038/ ismej.2017.49.

9. Pedler BE, Aluwihare LI, Azam F. Single bacterial strain capable of significant contribution to carbon cycling in the surface ocean. Proc Natl Acad Sci USA. 2014;111:7202-7.

10. Aharonovich D, Sher D. Transcriptional response of Prochlorococcus to co-culture with a marine Alteromonas: differences between strains and the involvement of putative infochemicals. ISME J. 2016;10:2892-906.

11. Morris JJ, Kirkegaard R, Szul MJ, Johnson ZI, Zinser ER. Facilitation of robust growth of Prochlorococcus colonies and 
dilute liquid cultures by 'helper' heterotrophic bacteria. Appl Environ Microbiol. 2008;74:4530-4.

12. Sher D, Thompson JW, Kashtan N, Croal L, Chisholm SW. Response of Prochlorococcus ecotypes to co-culture with diverse marine bacteria. ISME J. 2011;5:1125-32.

13. Diner RE, Schwenck SM, McCrow JP, Zheng H, Allen AE. Genetic manipulation of competition for nitrate between heterotrophic bacteria and diatoms. Front Microbiol. 2016;7:880.

14. Hewson I, Poretsky RS, Dyhrman ST, Zielinski B, White AE, Tripp HJ, et al. Microbial community gene expression within colonies of the diazotroph, Trichodesmium, from the Southwest Pacific Ocean. ISME J. 2009;3:1286-1300.

15. Zwart G, Crump BC, Kamst-van Agterveld MP, Hagen F, Han S-K. Typical freshwater bacteria: an analysis of available $16 \mathrm{~S}$ rRNA gene sequences from plankton of lakes and rivers. Aquat Microb Ecol. 2002;28:141-55.

16. Simonato F, Gómez-Pereira PR, Fuchs BM, Amann R. Bacterioplankton diversity and community composition in the Southern Lagoon of Venice. Syst Appl Microbiol. 2010;33:128-38.

17. McCarren J, Becker JW, Repeta DJ, Shi Y, Young CR, Malmstrom RR, et al. Microbial community transcriptomes reveal microbes and metabolic pathways associated with dissolved organic matter turnover in the sea. Proc Natl Acad Sci USA. 2010;107:16420-7.

18. Shi Y, McCarren J, DeLong EF. Transcriptional responses of surface water marine microbial assemblages to deep-sea water amendment. Environ Microbiol. 2012;14:191-206.

19. Spungin D, Pfreundt U, Berthelot H, Bonnet S, AlRoumi D, Natale F, et al. Mechanisms of Trichodesmium demise within the New Caledonian lagoon during the VAHINE mesocosm experiment. Biogeosciences. 2016;13:4187-203.

20. Tada Y, Taniguchi A, Nagao I, Miki T, Uematsu M, Tsuda A, et al. Differing growth responses of major phylogenetic groups of marine bacteria to natural phytoplankton blooms in the western North Pacific Ocean. Appl Environ Microbiol. 2011;77:4055-65.

21. Acinas SG, Antón J, Rodríguez-Valera F. Diversity of free-living and attached bacteria in offshore Western Mediterranean waters as depicted by analysis of genes encoding 16S rRNA. Appl Environ Microbiol. 1999;65:514-22.

22. Ivars-Martinez E, Martin-Cuadrado A-B, D'Auria G, Mira A, Ferriera S, Johnson J, et al. Comparative genomics of two ecotypes of the marine planktonic copiotroph Alteromonas macleodii suggests alternative lifestyles associated with different kinds of particulate organic matter. ISME J. 2008;2:1194-212.

23. López-López A, Bartual SG, Stal L, Onyshchenko O, RodríguezValera F. Genetic analysis of housekeeping genes reveals a deepsea ecotype of Alteromonas macleodii in the Mediterranean Sea. Environ Microbiol. 2005;7:649-59.

24. Seymour JR, Amin SA, Raina J-B, Stocker R. Zooming in on the phycosphere: the ecological interface for phytoplankton-bacteria relationships. Nat Microbiol. 2017;2:17065.

25. Smriga S, Fernandez VI, Mitchell JG, Stocker R. Chemotaxis toward phytoplankton drives organic matter partitioning among marine bacteria. Proc Natl Acad Sci USA. 2016;113:1576-81.

26. Stocker R. Marine microbes see a sea of gradients. Science. 2012;338:628-33.

27. López-Pérez M, Gonzaga A, Ivanova EP, Rodriguez-Valera F. Genomes of Alteromonas australica, a world apart. BMC Genom. 2014;15:483.

28. López-Pérez M, Gonzaga A, Martin-Cuadrado A-B, Onyshchenko O, Ghavidel A, Ghai R, et al. Genomes of surface isolates of Alteromonas macleodii: the life of a widespread marine opportunistic copiotroph. Sci Rep. 2012;2:696.

29. López-Pérez M, Gonzaga A, Rodriguez-Valera F. Genomic diversity of 'deep ecotype' Alteromonas macleodii isolates: evidence for Pan-Mediterranean clonal frames. Genome Biol Evol. 2013;5:1220-32.

30. Baker BJ, Sheik CS, Taylor CA, Jain S, Bhasi A, Cavalcoli JD, et al. Community transcriptomic assembly reveals microbes that contribute to deep-sea carbon and nitrogen cycling. ISME J. 2013;7:1962-73.

31. Pfreundt U, Spungin D, Bonnet S, Berman-Frank I, Hess WR. Global analysis of gene expression dynamics within the marine microbial community during the VAHINE mesocosm experiment in the southwest Pacific. Biogeosciences. 2016; 13:4135-49.

32. López-Pérez M, Rodriguez-Valera F. Pangenome evolution in the marine bacterium Alteromonas. Genome Biol Evol. 2016; 8:1556-70.

33. Kimes NE, López-Pérez M, Ausó E, Ghai R, Rodriguez-Valera F. RNA sequencing provides evidence for functional variability between naturally co-existing Alteromonas macleodii lineages. BMC Genom. 2014;15:938.

34. Biller SJ, Coe A, Chisholm SW. Torn apart and reunited: impact of a heterotroph on the transcriptome of Prochlorococcus. ISME J. 2016;10:2831-43.

35. Hou S, Pfreundt U, Miller D, Berman-Frank I, Hess WR. mdRNA-Seq analysis of marine microbial communities from the northern Red Sea. Sci Rep. 2016;6:35470.

36. Chen Y-B, Zehr JP, Mellon M. Growth and nitrogen fixation of the diazotrophic filamentous nonheterocystous cyanobacterium Trichodesmium sp. IMS 101 in defined media: evidence for a circadian rhythm. J Phycol. 1996;32:916-23.

37. De Marsac NT, Houmard J. [34] Complementary chromatic adaptation: physiological conditions and action spectra. Methods Enzymol. 1988;167:318-28.

38. Pade N, Michalik D, Ruth W, Belkin N, Hess WR, BermanFrank I, et al. Trimethylated homoserine functions as the major compatible solute in the globally significant oceanic cyanobacterium Trichodesmium. Proc Natl Acad Sci USA. 2016;113:13191-6.

39. Pfreundt U, Kopf M, Belkin N, Berman-Frank I, Hess WR. The primary transcriptome of the marine diazotroph Trichodesmium erythraeum IMS101. Sci Rep. 2014a;4:6187.

40. Coleman ML, Sullivan MB, Martiny AC, Steglich C, Barry K, Delong EF, et al. Genomic islands and the ecology and evolution of Prochlorococcus. Science. 2006;311: 1768-70.

41. Richter M, Rosselló-Móra R. Shifting the genomic gold standard for the prokaryotic species definition. Proc Natl Acad Sci USA. 2009; 106:19126-31.

42. Tatusov RL, Galperin MY, Natale DA, Koonin EV. The COG database: a tool for genome-scale analysis of protein functions and evolution. Nucleic Acids Res. 2000;28:33-36.

43. Lassmann T, Sonnhammer ELL. Kalign--an accurate and fast multiple sequence alignment algorithm. BMC Bioinforma. 2005;6:298

44. Price MN, Dehal PS, Arkin AP. FastTree 2 - approximately maximum-likelihood trees for large alignments. PLoS ONE. 2010;5:e9490.

45. Hoffmann S, Otto C, Kurtz S, Sharma CM, Khaitovich P, Vogel $\mathrm{J}$, et al. Fast mapping of short sequences with mismatches, insertions and deletions using index structures. PLoS Comput Biol. 2009;5:e1000502.

46. Robinson MD, McCarthy DJ, Smyth GK. edgeR: a Bioconductor package for differential expression analysis of digital gene expression data. Bioinformatics. 2010;26:139-40.

47. Naghdi MR, Smail K, Wang JX, Wade F, Breaker RR, Perreault J. Search for 5'-leader regulatory RNA structures based on gene annotation aided by the RiboGap database. Methods San Diego Calif. 2017;117:3-13. 
48. Kulkarni PR, Jia T, Kuehne SA, Kerkering TM, Morris ER, Searle MS, et al. A sequence-based approach for prediction of CsrA/RsmA targets in bacteria with experimental validation in Pseudomonas aeruginosa. Nucleic Acids Res. 2014;42:6811-25.

49. Luehr S, Hartmann H, Söding J. The XXmotif web server for eXhaustive, weight matriX-based motif discovery in nucleotide sequences. Nucleic Acids Res. 2012;40:W104-109.

50. Ridgway NM. Temperature and salinity of sea water at the ocean floor in the New Zealand region. N Z J Mar Freshw Res. 1969;3:57-72.

51. Talley LD. Salinity patterns in the ocean. Earth Syst Phys Chem Dimens Glob Environ Change. 2002;1:629-40.

52. Genin A, Lazar B, Brenner S. Vertical mixing and coral death in the Red Sea following the eruption of Mount Pinatubo. Nature. 1995;377:507-10.

53. Pfreundt U, Miller D, Adusumilli L, Stambler N, Berman-Frank I, Hess WR. Depth dependent metatranscriptomes of the marine pico-/nanoplanktonic communities in the Gulf of Aqaba/Eilat during seasonal deep mixing. Mar Genom. 2014b;18:93-95.

54. Rodriguez-Valera F, Martin-Cuadrado A-B, López-Pérez M. Flexible genomic islands as drivers of genome evolution. Curr Opin Microbiol. 2016;31:154-60.

55. Mizuno CM, Kimes NE, López-Pérez M, Ausó E, RodriguezValera F, Ghai R. A hybrid NRPS-PKS gene cluster related to the bleomycin family of antitumor antibiotics in Alteromonas macleodii strains. PLoS ONE. 2013;8:e76021.

56. Alkhateeb RS, Vorhölter F-J, Rückert C, Mentz A, Wibberg D, Hublik G, et al. Genome wide transcription start sites analysis of Xanthomonas campestris pv. campestris B100 with insights into the gum gene cluster directing the biosynthesis of the exopolysaccharide xanthan. J Biotechnol. 2016;225:18-28.

57. Voigt K, Sharma CM, Mitschke J, Joke Lambrecht S, Voß B, Hess WR, et al. Comparative transcriptomics of two environmentally relevant cyanobacteria reveals unexpected transcriptome diversity. ISME J. 2014;8:2056-68.

58. Dugar G, Herbig A, Förstner KU, Heidrich N, Reinhardt R, Nieselt $\mathrm{K}$, et al. High-resolution transcriptome maps reveal strain-specific regulatory features of multiple Campylobacter jejuni isolates. PLoS Genet. 2013;9:e1003495.

59. Kopf M, Klähn S, Scholz I, Hess WR, Voß B. Variations in the non-coding transcriptome as a driver of inter-strain divergence and physiological adaptation in bacteria. Sci Rep. 2015;5:9560.

60. Li J, Qi L, Guo Y, Yue L, Li Y, Ge W, et al. Global mapping transcriptional start sites revealed both transcriptional and posttranscriptional regulation of cold adaptation in the methanogenic archaeon Methanolobus psychrophilus. Sci Rep. 2015a;5:9209.

61. Papenfort K, Förstner KU, Cong J-P, Sharma CM, Bassler BL. Differential RNA-seq of Vibrio cholerae identifies the VqmR small RNA as a regulator of biofilm formation. Proc Natl Acad Sci USA. 2015;112:E766-775.

62. Sharma CM, Hoffmann S, Darfeuille F, Reignier J, Findeiss S, Sittka A, et al. The primary transcriptome of the major human pathogen Helicobacter pylori. Nature. 2010;464:250-5.

63. Serra DO, Hengge R. Stress responses go three dimensional - the spatial order of physiological differentiation in bacterial macrocolony biofilms. Environ Microbiol. 2014;16:1455-71.

64. Weber H, Polen T, Heuveling J, Wendisch VF, Hengge R. Genome-wide analysis of the general stress response network in Escherichia coli: $\sigma$ S-dependent genes, promoters, and sigma factor selectivity. J Bacteriol. 2005;187:1591-603.

65. Battesti A, Majdalani N, Gottesman S. The RpoS-mediated general stress response in Escherichia coli. Annu Rev Microbiol. 2011;65:189-213.

66. Yildiz FH, Schoolnik GK. Role of rpoS in stress survival and virulence of Vibrio cholerae. J Bacteriol. 1998;180:773-84.
67. Fang FC, Libby SJ, Buchmeier NA, Loewen PC, Switala J, Harwood J, et al. The alternative sigma factor $k a t F(r p o S)$ regulates Salmonella virulence. Proc Natl Acad Sci USA. 1992;89:11978-82.

68. Dong T, Joyce C, Schellhorn HE, Dong T, Joyce C. The role of RpoS in bacterial adaptation. Bacterial Physiology. Berlin, Heidelberg: Springer; 2008. p. 313-37.

69. Ito A, May T, Kawata K, Okabe S. Significance of rpoS during maturation of Escherichia coli biofilms. Biotechnol Bioeng. 2008;99:1462-71.

70. Dong T, Yu R, Schellhorn H. Antagonistic regulation of motility and transcriptome expression by RpoN and RpoS in Escherichia coli. Mol Microbiol. 2011;79:375-86.

71. Dudin O, Geiselmann J, Ogasawara H, Ishihama A, Lacour S. Repression of flagellar genes in exponential phase by CsgD and CpxR, two crucial modulators of Escherichia coli biofilm formation. J Bacteriol. 2014;196:707-15.

72. Pinhassi J, Berman T. Differential growth response of colonyforming alpha- and gamma-proteobacteria in dilution culture and nutrient addition experiments from Lake Kinneret (Israel), the eastern Mediterranean Sea, and the Gulf of Eilat. Appl Environ Microbiol. 2003;69:199-211.

73. Sakami T, Watanabe T, Kakehi S, Taniuchi Y, Kuwata A. Spatial variation of bacterial community composition at the expiry of spring phytoplankton bloom in Sendai Bay, Japan. Gene. 2016;576:610-7.

74. Schä H, Bernard L, Courties C, Lebaron P, Servais P, Pukall R, et al. Microbial community dynamics in Mediterranean nutrientenriched seawater mesocosms: changes in the genetic diversity of bacterial populations. FEMS Microbiol Ecol. 2001; 34:243-53.

75. Li M, Baker BJ, Anantharaman K, Jain S, Breier JA, Dick GJ. Genomic and transcriptomic evidence for scavenging of diverse organic compounds by widespread deep-sea archaea. Nat Commun. 2015b;6:8933.

76. Lloyd KG, Schreiber L, Petersen DG, Kjeldsen KU, Lever MA, Steen $\mathrm{AD}$, et al. Predominant archaea in marine sediments degrade detrital proteins. Nature. 2013;496:215-8.

77. Martin-Cuadrado A-B, Garcia-Heredia I, Moltó AG, LópezÚbeda R, Kimes N, López-García P, et al. A new class of marine Euryarchaeota group II from the Mediterranean deep chlorophyll maximum. ISME J. 2015;9:1619-34.

78. Park HJ, Lee YM, Kim S, Wi AR, Han SJ, Kim H-W, et al. Identification of proteolytic bacteria from the Arctic Chukchi Sea expedition cruise and characterization of cold-active proteases. $\mathbf{J}$ Microbiol. 2014;52:825-33.

79. Gur E, Biran D, Ron EZ. Regulated proteolysis in Gram-negative bacteria--how and when? Nat Rev Microbiol. 2011;9:839-48.

80. Rosen R, Biran D, Gur E, Becher D, Hecker M, Ron EZ. Protein aggregation in Escherichia coli: role of proteases. FEMS Microbiol Lett. 2002;207:9-12.

81. Allers E, Gómez-Consarnau L, Pinhassi J, Gasol JM, Šimek K, Pernthaler J. Response of Alteromonadaceae and Rhodobacteriaceae to glucose and phosphorus manipulation in marine mesocosms. Environ Microbiol. 2007;9:2417-29.

82. Wietz M, Wemheuer B, Simon H, Giebel H-A, Seibt MA, Daniel $\mathrm{R}$, et al. Bacterial community dynamics during polysaccharide degradation at contrasting sites in the Southern and Atlantic Oceans. Environ Microbiol. 2015;17:3822-31.

83. Neumann AM, Balmonte JP, Berger M, Giebel H-A, Arnosti C, Voget $\mathrm{S}$, et al. Different utilization of alginate and other algal polysaccharides by marine Alteromonas macleodii ecotypes. Environ Microbiol. 2015;17:3857-68.

84. Berman-Frank I, Rosenberg G, Levitan O, Haramaty L, Mari X. Coupling between autocatalytic cell death and transparent 
exopolymeric particle production in the marine cyanobacterium Trichodesmium. Environ Microbiol. 2007;9:1415-22.

85. Berman-Frank I, Bidle KD, Haramaty L, Falkowski PG. The demise of the marine cyanobacterium, Trichodesmium spp., via an autocatalyzed cell death pathway. Limnol Oceanogr. 2004:49:997-1005.

86. Repoila F, Darfeuille F. Small regulatory non-coding RNAs in bacteria: physiology and mechanistic aspects. Biol Cell. 2009;101:117-31.

87. Dubey AK, Baker CS, Suzuki K, Jones AD, Pandit P, Romeo T, et al. CsrA regulates translation of the Escherichia coli carbon starvation gene, cstA, by blocking ribosome access to the $\operatorname{cstA}$ transcript. J Bacteriol. 2003;185:4450-60.

88. Moreno R, Ruiz-Manzano A, Yuste L, Rojo F. The Pseudomonas putida Crc global regulator is an RNA binding protein that inhibits translation of the AlkS transcriptional regulator. Mol Microbiol. 2007;64:665-75.

89. Romeo T, Gong M, Liu MY, Brun-Zinkernagel A-M. Identification and molecular characterization of $\operatorname{cs} r A$, a pleiotropic gene from Escherichia coli that affects glycogen biosynthesis, gluconeogenesis, cell size, and surface properties. J Bacteriol. 1993; 175:4744-55.

90. Babitzke P, Romeo T. CsrB sRNA family: sequestration of RNA-binding regulatory proteins. Curr Opin Microbiol. 2007;10:156-63.

91. Romeo T. Global regulation by the small RNA-binding protein CsrA and the non-coding RNA molecule CsrB. Mol Microbiol. 1998;29:1321-30.

92. Romeo T, Vakulskas CA, Babitzke P. Post-transcriptional regulation on a global scale: form and function of Csr/Rsm systems. Environ Microbiol. 2013;15:313-24.

93. Seyll E, Van Melderen L. The ribonucleoprotein Csr network. Int J Mol Sci. 2013;14:22117-31.

94. Valverde C, Lindell M, Wagner EGH, Haas D. A repeated GGA motif is critical for the activity and stability of the riboregulator RsmY of Pseudomonas fluorescens. J Biol Chem. 2004;279:25066-74.

95. Heroven AK, Böhme K, Dersch P. The Csr/Rsm system of Yersinia and related pathogens: a post-transcriptional strategy for managing virulence. RNA Biol. 2012;9:379-91.
96. Heroven AK, Böhme K, Rohde M, Dersch P. A Csr-type regulatory system, including small non-coding RNAs, regulates the global virulence regulator RovA of Yersinia pseudotuberculosis through RovM. Mol Microbiol. 2008;68:1179-95.

97. Liu MY, Gui G, Wei B, Preston JF, Oakford L, Yüksel U, et al. The RNA molecule CsrB binds to the global regulatory protein CsrA and antagonizes its activity in Escherichia coli. J Biol Chem. 1997;272:17502-10.

98. Liu Y, Cui Y, Mukherjee A, Chatterjee AK. Characterization of a novel RNA regulator of Erwinia carotovora ssp. carotovora that controls production of extracellular enzymes and secondary metabolites. Mol Microbiol. 1998;29:219-34.

99. Sahr T, Brüggemann H, Jules $M$, Lomma M, AlbertWeissenberger C, Cazalet $C$, et al. Two small ncRNAs jointly govern virulence and transmission in Legionella pneumophila. Mol Microbiol. 2009;72:741-62.

100. Sahr T, Rusniok C, Impens F, Oliva G, Sismeiro O, Coppée J-Y, et al. The Legionella pneumophila genome evolved to accommodate multiple regulatory mechanisms controlled by the CsrAsystem. PLoS Genet. 2017;13:e1006629.

101. Wang X, Dubey AK, Suzuki K, Baker CS, Babitzke P, Romeo T. CsrA post-transcriptionally represses pgaABCD, responsible for synthesis of a biofilm polysaccharide adhesin of Escherichia coli. Mol Microbiol. 2005;56:1648-63.

102. Bhatt S, Edwards AN, Nguyen HTT, Merlin D, Romeo T, Kalman D. The RNA binding protein CsrA is a pleiotropic regulator of the locus of enterocyte effacement pathogenicity island of enteropathogenic Escherichia coli. Infect Immun. 2009;77:3552-68.

103. Yang H, Liu MY, Romeo T. Coordinate genetic regulation of glycogen catabolism and biosynthesis in Escherichia coli via the CsrA gene product. J Bacteriol. 1996;178:1012-7.

104. Lenz DH, Miller MB, Zhu J, Kulkarni RV, Bassler BL. CsrA and three redundant small RNAs regulate quorum sensing in Vibrio cholerae. Mol Microbiol. 2005;58:1186-202.

105. Kim D, Song L, Breitwieser FP, Salzberg SL. Centrifuge: rapid and sensitive classification of metagenomic sequences. Genome Res. 2016;26:1721-9.

106. Supek F, Bošnjak M, Škunca N, Šmuc T. REVIGO summarizes and visualizes long lists of gene ontology terms. PLoS ONE. 2011;6:e21800. 